Review

\title{
Solvothermal Synthesis of Multifunctional Coordination Polymers
}

Yonggang Zhao, Kunhao Li, and Jing Li

Department of Chemistry and Chemical Biology, Rutgers University, Piscataway, NJ 08854, USA

Reprint requests to Prof. Dr. Jing Li. Fax: 732-445-5312. E-mail: jingli@ rutgers.edu

Z. Naturforsch. 2010, 65b, 976-998; received March 31, 2010

This review focuses primarily on the past 10 years of our development of multifunctional coordination polymers with 1D, 2D and 3D structures employing low-temperature and cost-effective hydrothermal and solvothermal methods. The effects of the experimental conditions and parameters on the crystal formation and phase separation, including temperature and pressure, reaction $\mathrm{pH}$, solvent and composition, are discussed. Our studies have shown that a variety of different types of network structures may be rationally designed and synthesized by deliberate selection and construction of metal building blocks and organic ligands, which lead to numerous interesting properties and multifunctionality that are promising for applications in gas storage and separation, catalysis and optical sensing.

Key words: Solvothermal Synthesis, Coordination Polymer, Metal-Organic Framework, Porosity, Multifunctionality

\section{Introduction}

\section{Coordination polymers: Background and history}

As one of the most attractive and challenging research areas of chemistry and material science, the study of novel coordination polymers, also referred as metal-organic frameworks (MOFs), is undergoing a burgeoning development [1-7]. Coordination polymers are known as compounds containing both inorganic units and organic ligands as integral parts which extend to one-, two- and three-dimensional infinite networks through coordinative bonding connectivity [8-10]. As a rule, coordination polymers are solids.
The structural features of these solid-state materials are typically governed by three aspects: the connectors (metal or metal clusters); linkers (ligand molecules); and their connectivity. Many intriguing properties of these materials rely on their structures and topology. Thus by employing well-chosen starting materials, coordination polymers possessing fascinating structures and interesting properties can be rationally and deliberately designed and synthesized. To date, much work in this field has demonstrated that the tailoring nature of structures and functionalities has made coordination polymers promising candidates in various applications, including adsorption,

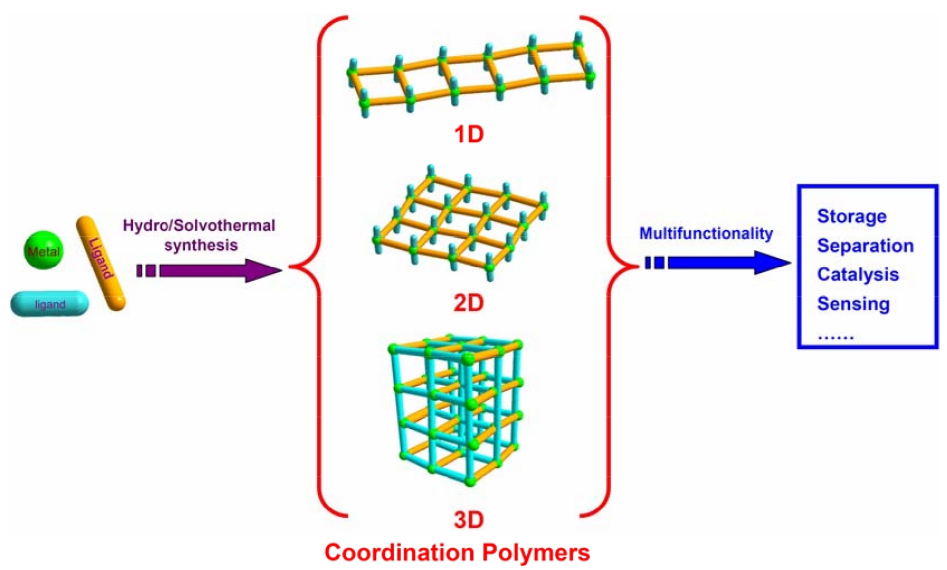

0932-0776 / 10 / 0800-976 \$ 06.00 @ 2010 Verlag der Zeitschrift für Naturforschung, Tübingen · http://znaturforsch.com 
separation, catalysis, magnetism, sensing, and hostguest chemistry [11-14].

While the term "coordination polymer" was first introduced a long time ago in the early 1960s [15], strong interests began to grow only after 30 years, bringing together researchers across the world to work in this field. Robson and coworkers $[16,17]$ delineated principles of coordination polymers and extrapolated Wells' work [18] to infinite metal organic frameworks. Later on, Zaworotko [19,20], Fujita [21,22], Kitagawa [23-25], Férey [26,27] and others contributed to expand the structure database by using net-based approach. Studies by Yaghi and coworkers revealed the tremendous potential in adsorption-related applications of open framework coordination polymers, or porous metal-organic frameworks, and illustrated the strategies for construction of MOFs with control of their vertex geometry, functionality, and pore characteristics, giving a leap in accelerating the pace of development [28-31]. Since the 1990s, thousands of publications on this remarkable class of materials have appeared.

\section{Coordination polymers: Synthesis and crystal growth}

Among numerous synthetic methods and techniques used for the preparation of solid materials, solvother$\mathrm{mal} / \mathrm{hydrothermal} \mathrm{methods} \mathrm{have} \mathrm{been} \mathrm{confirmed} \mathrm{to} \mathrm{be}$ among the most effective and convenient routes under relatively mild conditions, in particular for the crystal growth of coordination polymers [32-34]. Solvothermal reactions involve the use of an organic or inorganic solvent at elevated temperature and autogeneous pressure in a sealed system (usually Teflon-lined autoclaves or glass vials) [35]. When water is used as the solvent, the reactions are referred to as hydrothermal. Solvents, under such subcritical and supercritical conditions, undergo a dramatic change in many of their properties, such as density, viscosity, and diffusion coefficient, etc. Consequently, the diffusion and reactivity of chemical species are greatly enhanced, and many reactions can occur at much lower temperatures.

For the determination of the topology, dimensionality and porosity of coordination polymers, obtaining high-quality single crystals suitable for X-ray diffraction analysis has become essential. While the solvothermal process has been found to be an efficient solution to the problems often encountered in the crystal growth using traditional solution or diffusion methods [36], a successful synthesis of a targeted coordination polymer will depend largely on the experimental conditions. Many reaction parameters need to be considered, including composition of the reactants, temperature and pressure, concentration, reaction time, $\mathrm{pH}$ value and solubility, to name a few [37]. As the crystallization under solvothermal conditions is often a nonequilibrium process and may give rise to metastable products, the cooling rate at the end of the reaction is also an important parameter to take into consideration. Selection of the solvent is very important, since some metal salts and/or organic ligands have very low solubility or are even insoluble in a given solvent. In some cases, introducing two or three solvents and ultrasonic pretreatment may be helpful to increase solubility. Moreover, solvents play crucial roles as the structure directing, templating, and pore-filling agents during the formation of coordination polymers.

This review does not intend to give a comprehensive coverage of the coordination polymers synthesized by solvo(hydro)thermal methods. Rather, it will focus mainly on our own contributions using this approach over the past decade, and on the relationships between the synthesis, the crystal and pore structures and the functionality of these materials.

\section{Solvo(hydro)thermal Synthesis of Selected Com- pounds}

\section{Hydrothermal reactions}

Our early work had centered on the design and preparation of coordination polymers by employing hydrothermal reactions. In the case of the formation of one-dimensional $\mathrm{Cu}$-dpa $\left(\mathrm{dpa}=2,2^{\prime}\right.$-dipyridylamine $)$ structures, the stoichiometry of the starting materials was the most important parameter affecting the final products [38]. Heating a mixture of $\mathrm{CuCl}_{2} \cdot 2 \mathrm{H}_{2} \mathrm{O}$ $(0.1705 \mathrm{~g})$ and dpa $(0.1712 \mathrm{~g})$ at $1: 1$ ratio in $\mathrm{H}_{2} \mathrm{O}$ $(5 \mathrm{~mL})$ in an acid digestion bomb at $170{ }^{\circ} \mathrm{C}$ afforded the compound $\left[(\mathrm{CuCl})_{2}(\mathrm{dpiz})\right](\mathbf{1})$ as orange crystals. Structure analysis has revealed that the dpa ligand was rearranged to give rise to the formation of dpiz ([1,2$\mathrm{a}: 2^{\prime}, 3^{\prime}$-d]imidazole) in situ during the hydrothermal process (Scheme 1), in which the 1D Cu-dipz-halide polymer was formed (Fig. 1a). In compound $\mathbf{1}, \mathrm{Cu}(1)$ and $\mathrm{Cu}(2)$, having different coordination configuration, are connected and extend to one-dimensional chains

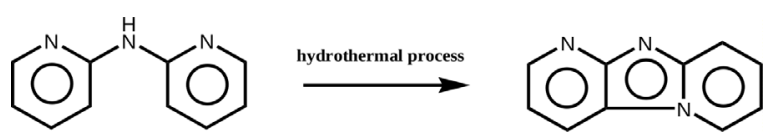

Scheme 1. 


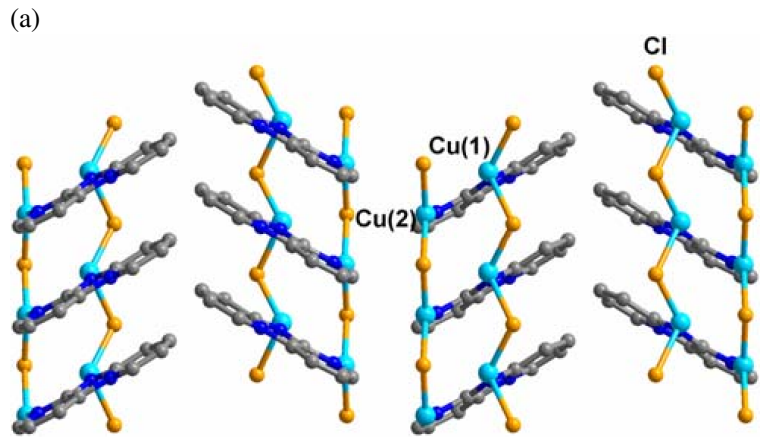

(b)

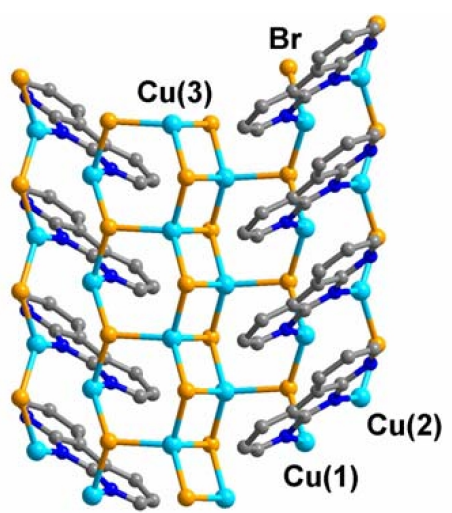

Fig. 1 (color online). Perspective view of the onedimensional chain structures of compounds 1 (a, view along the $b$ axis) and $\mathbf{2}$ (b, view along the $c$ axis). $\mathrm{Cu}$ (turquoise), $\mathrm{Cl} / \mathrm{Br}$ (orange), $\mathrm{N}$ (blue) and $\mathrm{C}$ (gray).

via $\mu_{2}-\mathrm{Cl}$ and $\mu_{3}-\mathrm{Cl}$ atoms. However, using the same experimental condition, the reaction of $\mathrm{CuBr}_{2}$, dpa and $\mathrm{H}_{2} \mathrm{O}$ in a molar ration of $2: 1: 334$ gave orange crystals of the compound $\left[(\mathrm{CuBr})_{3}(\mathrm{dpiz})\right](\mathbf{2})$. The structure of compound $\mathbf{2}$ is in part similar to that of compound $\mathbf{1}$ but an additional infinite $\mathrm{Cu}_{2} \mathrm{Br}_{2}$ zigzag double chain is found between every other pair of $(\mathrm{CuBr})_{2}(\mathrm{dpiz})$ chains to give a one-dimensional ribbon-like structure (Fig. 1b). The three chains are connected via $\mathrm{Cu}(3)$ ( $\left.\mu_{2}-\mathrm{Br}\right)$ bonds, where $\mathrm{Cu}(3)$ is the third crystallographically independent copper site in this structure. The reactions of compounds $\mathbf{1}$ and $\mathbf{2}$ involved reduction of $\mathrm{Cu}(\mathrm{II})$ to $\mathrm{Cu}(\mathrm{I})$ and chemical rearrangement of dpa to dpiz, which was stimulated under the hydrothermal conditions. This study was one of the very first examples of the solvo(hydro)thermal synthesis of coordination polymers featuring one-pot and in situ ligand generation.

Compound $\left[(\mathrm{CuBr})_{2}\right.$ bpy $]$ (3) (bpy = 4,4'-bipyridine) was prepared by the reaction of $\mathrm{CuBr}_{2}$ and bpy in water with the molar ratio being $1: 1: 167$. The mixture was (a)

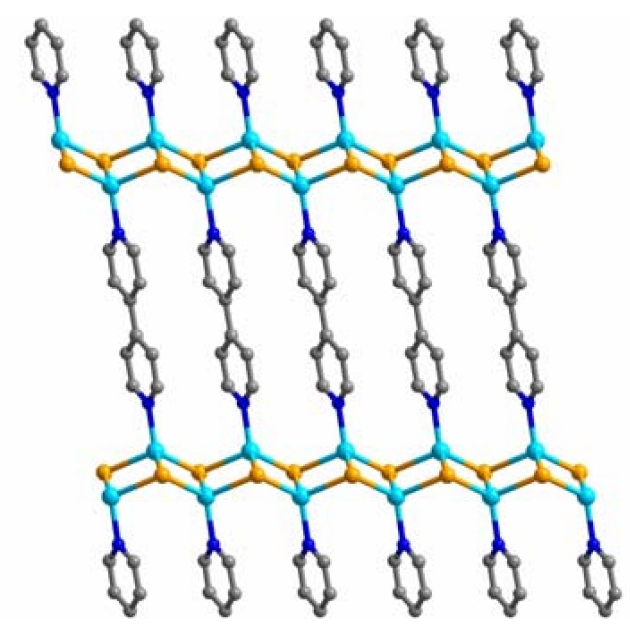

(b)

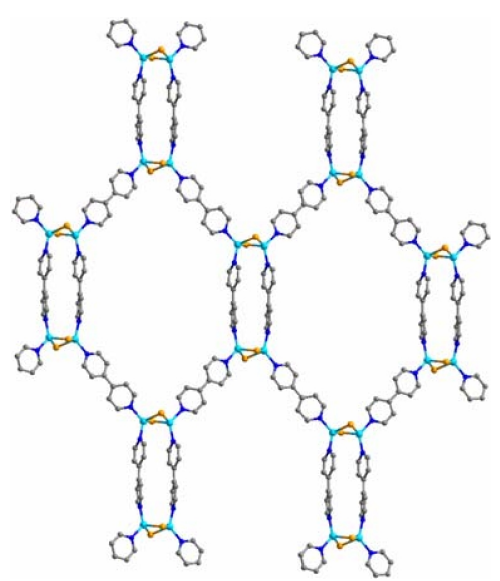

Fig. 2 (color online), a) Perspective view of the twodimensional layer in compound $\mathbf{3}$ along the $c$ axis; b) structure of the interlocking planar net in $\mathbf{4}$. The octagonal ring is shown in the center. $\mathrm{Cu}$ (turquoise), $\mathrm{Br}$ (orange), $\mathrm{N}$ (blue) and $\mathrm{C}$ (gray).

loaded in a $23 \mathrm{~mL}$ acid digestion bomb and heated at $170{ }^{\circ} \mathrm{C}$ for $7 \mathrm{~d}$ to yield dark-yellow crystals [39]. Compound 3 consists of the aforementioned $\mathrm{Cu}_{2} \mathrm{X}_{2}$ zigzag double chains shown in compound 2 (Fig. 2a). These $\mathrm{Cu}_{2} \mathrm{X}_{2}$ chains are further connected by bpy ligands to form two-dimensional layers in the $a b$ plane.

Increasing the amount of bpy by a factor of 2 against copper bromide (to the $2: 1$ ratio) while keeping other experimental conditions unchanged produced compound $[\mathrm{CuBr}(\mathrm{bpy})](4)$ in quantitative yield. The structure of compound 4 consists of four-fold interlocking planar 2D nets, which interpenetrate each other to give a three-dimensional framework structure (Fig. 2b). The planar networks are composed of large octagonal 


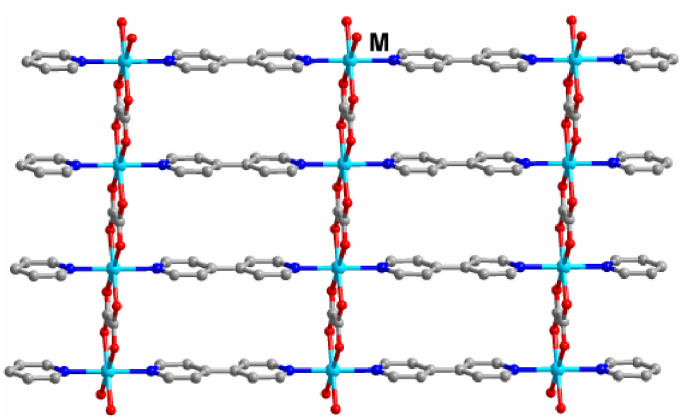

Fig. 3 (color online). Two-dimensional network of compounds 5-8 viewed along the $c$ axis. $M=\mathrm{Fe}, \mathrm{Co}, \mathrm{Ni}$ and Zn (turquoise), O (red), N (blue) and C (gray).

rings, formed by sharing bpy ligands and rectangular $\left[\left(\mathrm{Cu}_{2} \mathrm{Br}_{2}\right)(\text { bpy) }]_{2}\right.$ units. In compound $\mathbf{4}$, the stoichiometry has turned to $\mathrm{Cu}_{2} \mathrm{Br}_{2}$ (bpy) $)_{2}$.

Compounds 5-8 with the general formula $[M($ ox $)(\mathrm{bpy})](M=\mathrm{Fe}(\mathrm{II}),(\mathbf{5}) ; \mathrm{Co}(\mathrm{II}),(\mathbf{6}) ; \mathrm{Ni}(\mathrm{II}),(\mathbf{7})$; $\mathrm{Zn}(\mathrm{II}),(\mathbf{8})$; ox $=\mathrm{C}_{2} \mathrm{O}_{4}{ }^{2-}$ ) belong to a family of mixedligand coordination polymers having two-dimensional layered structures [40]. The general preparation procedure of compounds $\mathbf{5}-\mathbf{8}$ is described below. The mixture of $M X_{2}(X=\mathrm{Br}$ or $\mathrm{Cl})$, oxalic acid and bpy in the molar ratio of $1: 1: 1$ in $4 \mathrm{~mL}$ of $\mathrm{H}_{2} \mathrm{O}(8 \mathrm{~mL}$ for $\mathrm{Zn}$ ) was sealed in a $23 \mathrm{~mL}$ acid digestion bomb and heated at $170{ }^{\circ} \mathrm{C}$ for $7 \mathrm{~d}$. The crystals of the product were isolated by filtration and washed with water and acetone, then dried in air. X-Ray diffraction analysis has shown that the metal atoms are all six-coordinated to four oxygen atoms from oxalate ions and two nitrogen atoms from bpy ligands, forming a strictly rectangular grid in the $a b$ plane (Fig. 3). Adjacent layers stack on top of each other in a staggered fashion to complete the structure in the third dimension. Experiments show that the hydrothermal conditions are crucial for the formation and crystallization of compounds 5-8, since syntheses using $\mathrm{H}_{2} \mathrm{O}$ and other organic solvents all led to different products. The results of our study also indicate that the $\mathrm{pH}$ value of the solution will affect the crystallinity of products.

Three isostructural two-dimensional coordination polymers $\left[M \mathrm{Cl}_{2}\right.$ (bpy)] $[M=\mathrm{Fe}$ (II), (9); $\mathrm{Co}(\mathrm{II}),(\mathbf{1 0})$; $\mathrm{Ni}(\mathrm{II})$, (11)] were crystallized via the hydrothermal method (Fig. 4) [41]. Crystals or polycrystalline samples of 9-11 were obtained by heating the mixtures of $M \mathrm{Cl}_{x}(M=\mathrm{Fe}, \mathrm{Co}, \mathrm{Ni}, 1 \mathrm{mmol}$, for $\mathrm{Fe}, x=2$ or 3 ; for Co or $\mathrm{Ni}, x=2), \mathrm{H}_{2} \mathrm{C}_{2} \mathrm{O}_{4} \cdot 2 \mathrm{H}_{2} \mathrm{O}(1 \mathrm{mmol})$, bpy $(1 \mathrm{mmol})$ and $\mathrm{H}_{2} \mathrm{O}(5 \mathrm{~mL})$ in $23 \mathrm{~mL}$ acid digestion bombs at $170{ }^{\circ} \mathrm{C}$ for $7 \mathrm{~d}$. In compounds $9-\mathbf{1 1}$, metal

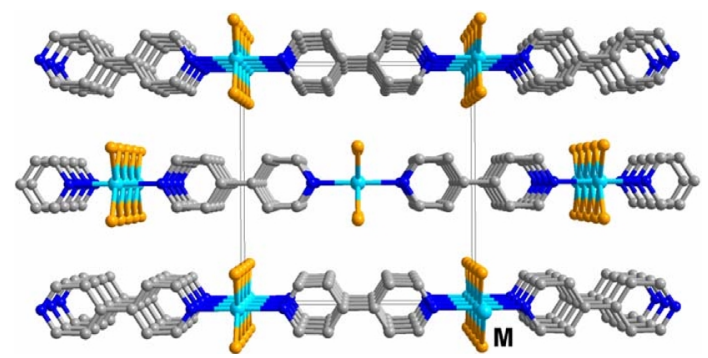

Fig. 4 (color online). Two-dimensional networks of compounds 9-11 viewed along the $b$ axis. $M=\mathrm{Fe}, \mathrm{Co}$ and $\mathrm{Ni}$ (turquoise), $\mathrm{Cl}$ (orange), $\mathrm{N}$ (blue), $\mathrm{C}$ (gray).

ions having octahedral coordination geometry are bridged by $\mu_{2}-\mathrm{Cl}$ to form 1D chains extending along the $c$ direction. These chains are interlinked by bpy ligands to form 2D layered networks in the $a c$ plane. The $\mathrm{M}-\mathrm{M}$ distances are in the range 3.58-3.62 $\mathrm{A}$.

Compared with the more extensively studied transition metal coordination polymers, rare earth metal coordination network compounds are relatively un-

(a)

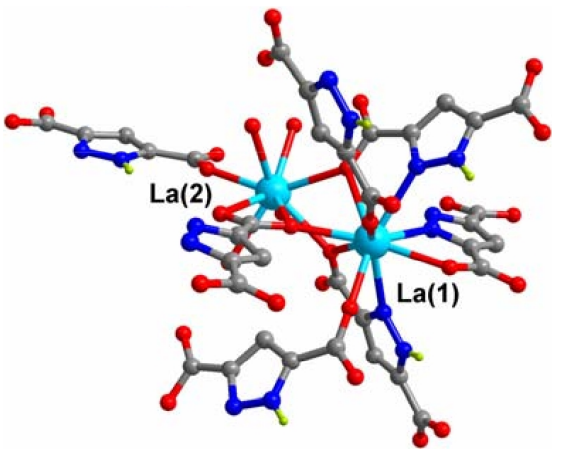

(b)

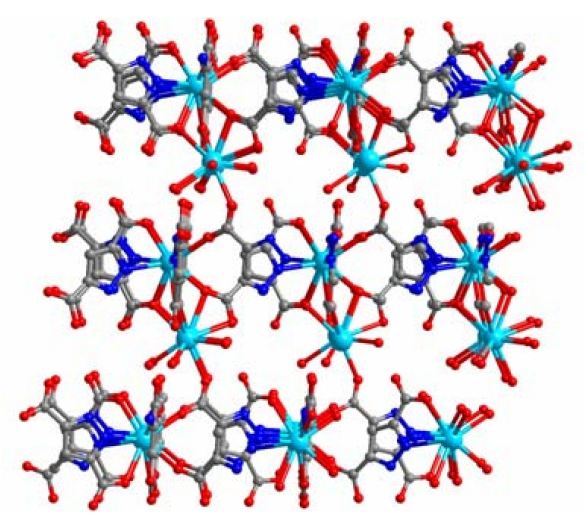

Fig. 5 (color online). Views of the coordination geometry around $\mathrm{La}(\mathrm{III})$ (a) and the three-dimensional structure (b) of compound 12. La (turquoise), O (red), N (blue), C (gray) and $\mathrm{H}$ (lime). 
common due to the large and variable coordination numbers and consequently more complicated structures $[42,43]$. Lanthanide coordination polymers 12-17 prepared by hydrothermal synthesis, feature 2D and 3D structures [44]. The compounds $\left[\operatorname{Ln}_{2}(\mathrm{Hpdc})_{3}\left(\mathrm{H}_{2} \mathrm{O}\right)_{4}\right] \cdot 2 \mathrm{H}_{2} \mathrm{O}[L n=\mathrm{La}(\mathbf{1 2})$ and $\mathrm{Ce}$ (13), $\mathrm{H}_{3}$ pdc $=3$,5-pyrazoledicarboxylic acid] were synthesized by heating the mixtures of $\mathrm{Ln}\left(\mathrm{NO}_{3}\right)_{3}$. $6 \mathrm{H}_{2} \mathrm{O}, \mathrm{H}_{3}$ pdc and $\mathrm{H}_{2} \mathrm{O}$ in the molar ratio of $1: 1: 2222$ in an $23 \mathrm{~mL}$ acid digestion bombs at $150{ }^{\circ} \mathrm{C}$ for 3 d. Compounds $\mathbf{1 2}$ and $\mathbf{1 3}$ feature three-dimensional structures containing nine-coordinated metal centers (Fig. 5). There are two crystallographically independent lanthanide sites in $\mathbf{1 2}$ and 13: $\operatorname{Ln} 1$ site is coordinated to six $\mathrm{Hpdc}^{2-}$ ligands, among which three $\mathrm{Hpdc}^{2-}$ ligands afford one carboxylate oxygen atom and an adjacent nitrogen atom each while the remaining three $\mathrm{Hpdc}^{2-}$ ligands only afford one single oxygen atom for coordination; $L n 2$ is coordinated to three oxygen atoms from three monodentate $\mathrm{Hpdc}^{2-}$ ligands, two oxygen atoms from one bidentate $\mathrm{Hpdc}^{2-}$ ligand and four oxygen atoms from four $\mathrm{H}_{2} \mathrm{O}$ molecules. Thus, the $\mathrm{Hpdc}^{2-}$ ligands have three different coordination modes in the structure.

The europium compound $\left[\mathrm{Eu}_{2}(\mathrm{Hpdc})_{3}\left(\mathrm{H}_{2} \mathrm{O}\right)_{6}\right]$ (14) was prepared under similar experimental conditions

(a)

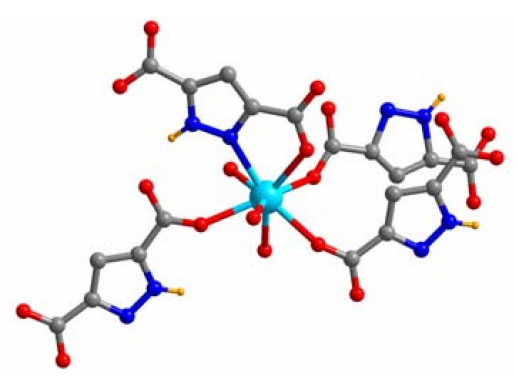

(b)

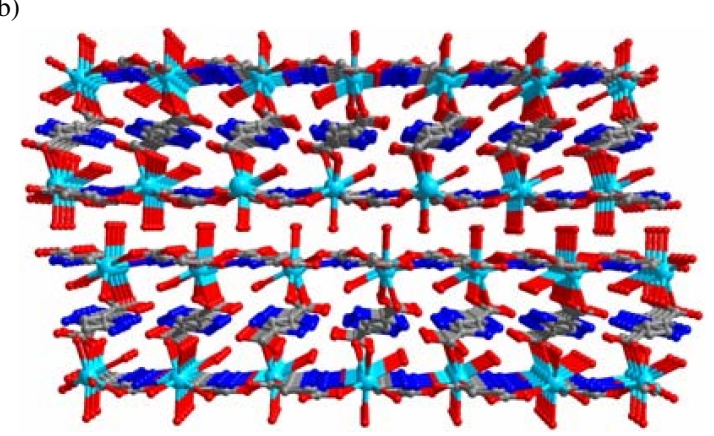

Fig. 6 (color online). View of the coordination geometry (a) and the double layer clay-like structure (b) of compound 14. $\mathrm{Eu}$ (turquoise), O (red), N (blue), C (gray) and H (lime). as for 12 and 13. It exhibits a rare clay-like double layer structure (Fig. 6). In 14, the Eu(III) centers are eight-coordinated with a square-antiprismatic geometry to three oxygen atoms from three separate $\mathrm{Hpdc}^{2-}$ ligands, one oxygen atom and an adjacent nitrogen atom from a fourth $\mathrm{Hpdc}^{2-}$ ligand, and three oxygen atoms afforded by three $\mathrm{H}_{2} \mathrm{O}$ molecules. The existence of two types of $\mathrm{Hpdc}^{2-}$ ligands results in a unique double-layer structure. Hydrogen bonding interactions are found between the double layers.

The erbium compound $\left[\mathrm{Er}(\mathrm{Hpdc})\left(\mathrm{H}_{2} \mathrm{pdc}\right)\left(\mathrm{H}_{2} \mathrm{O}\right)_{2}\right]$ (15) was prepared in an acidic environment $(\mathrm{pH}=1)$. Hydrated $\mathrm{Er}\left(\mathrm{NO}_{3}\right)_{3}, \mathrm{H}_{3}$ pdc, $\mathrm{HNO}_{3}$ and $\mathrm{H}_{2} \mathrm{O}$ (molar ratio: $1: 1: 1: 1111)$ were reacted in a $23 \mathrm{~mL}$ acid digestion bomb at $150{ }^{\circ} \mathrm{C}$ for $3 \mathrm{~d}$, and the pure product was collected after washing and drying in air. The lutetium compound [ $\left.\mathrm{Lu}(\mathrm{Hpdc})\left(\mathrm{H}_{2} \mathrm{pdc}\right)\left(\mathrm{H}_{2} \mathrm{O}\right)_{2}\right]$ (16) was prepared by a similar procedure as used for $12-$ 14. Structure analyses showed that both $\mathbf{1 5}$ and $\mathbf{1 6}$ have novel single-layered structures (Fig. 7), in which the lanthanide atoms are all eight-coordinated with $\mathrm{Hpdc}^{2-}, \mathrm{H}_{2} \mathrm{pdc}^{-}$and $\mathrm{H}_{2} \mathrm{O}$, respectively. There are two types of ligands involved in the coordination:

(a)
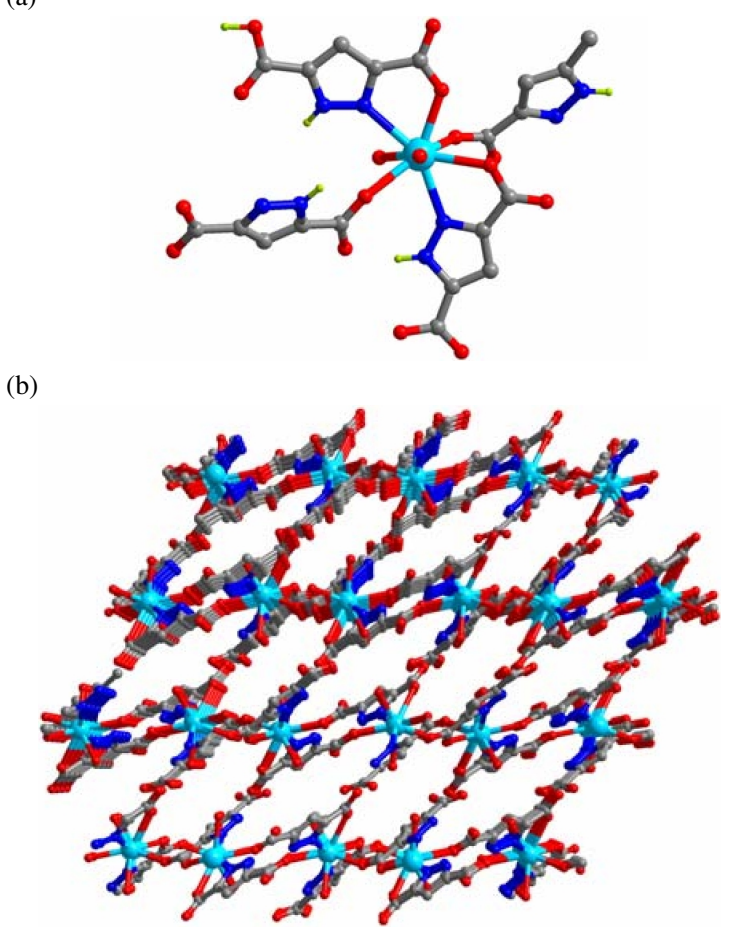

Fig. 7 (color online). View of the coordination geometry (a) and the single-layer structure (b) of compound 15. Er (turquoise), O (red), N (blue), C (gray) and H (lime). 
mono-deprotonated $\mathrm{H}_{2} \mathrm{pdc}^{-}$and dual-deprotonated $\mathrm{Hpdc}^{2-}$. In the mono-deprotonated $\mathrm{H}_{2} \mathrm{pdc}^{-}$ligand, only one carboxylate group can participate in the coordination, whereas both carboxylate groups of the dual-deprotonated $\mathrm{Hpdc}^{2-}$ ligands are available for coordination. By adjusting the level of deprotonation of the ligand, the double-layered erbium compound $\left[\mathrm{Er}_{2}(\mathrm{Hpdc})_{3}\left(\mathrm{H}_{2} \mathrm{O}\right)_{6}\right](\mathbf{1 7})$ that contains the dualdeprotonated $\mathrm{Hpdc}^{2-}$ ligand only was successfully isolated at $\mathrm{pH}=5$. This study indicates that the formation of products under hydrothermal conditions is easily affected by the acidity (or basicity) of the reaction medium. Structures with different coordination geometry and dimensionality may be achieved by controlling the $\mathrm{pH}$ value. In addition, the effect of lanthanide contraction is also found in the formation of these lanthanide coordination polymers, in accordance with the decreasing trend of coordination numbers from nine only for $\mathrm{La}(\mathrm{III})$ and $\mathrm{Ce}(\mathrm{III})$ compounds, to both nine and eight for $\mathrm{Eu}$ (III) compounds, and to eight only for Er(III) and Lu(III) compounds.

Using the same ligand $\mathrm{H}_{3}$ pdc, further research revealed that, when lanthanide ions are replaced by transition metal ions, three deprotonation processes (including the proton at a pyrazole nitrogen atom) may be controlled by the acidity of the reaction mixture (Scheme 2) [45].

$\mathbf{H}_{3} \mathbf{p d c} \underset{+\mathrm{H}}{\stackrel{-\mathrm{H}}{\rightleftharpoons}} \mathbf{H}_{2} \mathbf{p d c}=\stackrel{-\mathrm{H}}{\stackrel{-\mathrm{H}}{\rightleftharpoons}} \mathbf{H p d c}^{2-} \stackrel{-\mathrm{H}}{\underset{+\mathrm{H}}{\rightleftharpoons}} \mathbf{p d c}^{3-}$

Scheme 2. Protonation and deprotonation processes in $\mathrm{H}_{3}$ pdc.

The 3D cadmium coordination polymer $[\mathrm{Cd}(\mathrm{Hpdc})-$ $\left.\left(\mathrm{H}_{2} \mathrm{O}\right)\right](\mathbf{1 8})$ was assembled by hydrothermal reactions of $\mathrm{Cd}\left(\mathrm{NO}_{3}\right)_{2}(0.2 \mathrm{mmol}), \mathrm{H}_{3} \mathrm{pdc} \cdot \mathrm{H}_{2} \mathrm{O}(0.4 \mathrm{mmol})$ and $\mathrm{H}_{2} \mathrm{O}(10 \mathrm{~mL})$ in a Teflon-lined bomb at $150{ }^{\circ} \mathrm{C}$ for $12 \mathrm{~d}(\mathrm{pH}=2.5$ in the final solution). Yellowish block-like crystals of $\mathbf{1 8}$ were collected in high yields (98\%). In compound $\mathbf{1 8}$, the $\mathrm{Cd}(\mathrm{II})$ centers are sevencoordinated with adopting a pentagonal bipyramidal configuration (Fig. 8a). The resultant structure contains solely $\mathrm{Hpdc}^{2-}$ ligands coordinating the $\mathrm{Cd}(\mathrm{II})$ ions. Zigzag ribbons are found extending parallel to the $c$ axis formed through connecting neighboring $\mathrm{Cd}$ (II) ions with single bridging $\mathrm{Hpdc}^{2-}$. The inter-ribbon connections further result in the formation of a threedimensional structure. When the $\mathrm{pH}$ value of the reaction solution was changed from 2.5 to 4 by introducing $\mathrm{Et}_{3} \mathrm{~N}(0.5 \mathrm{mmol})$, reactions of $\mathrm{Cd}\left(\mathrm{NO}_{3}\right)_{2}(0.5 \mathrm{mmol})$ (a)

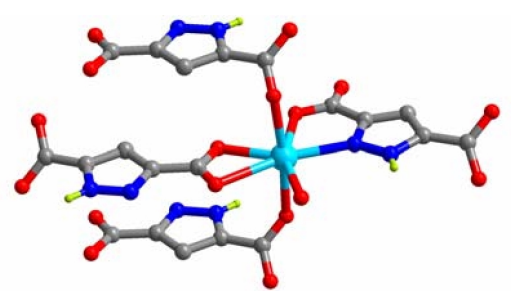

(b)

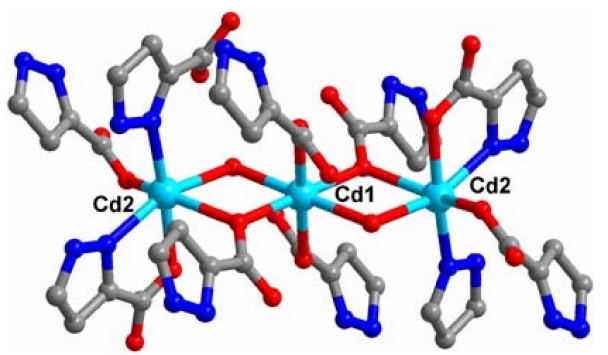

Fig. 8 (color online). View of the coordination geometry of compounds 18 (a) and 19 (b). Cd (turquoise), O (red), N (blue) and C (gray).

and $\mathrm{H}_{3}$ pdc $(0.25 \mathrm{mmol})$ in $\mathrm{H}_{2} \mathrm{O}(10 \mathrm{~mL})$ using the same temperature and time period gave a new $3 \mathrm{D}$ coordination network $\left[\mathrm{Cd}_{3}(\mathrm{pdc})_{2}\left(\mathrm{H}_{2} \mathrm{O}\right)_{2}\right](\mathbf{1 9})$ as paleyellow plate crystals. Though all $\mathrm{Cd}(\mathrm{II})$ ions are sixcoordinated in 19, two crystallographically independent metal sites are found in the structure (Fig. 8b). The ligands in $\mathbf{1 9}$ are in the fully deprotonated form of $\mathrm{pdc}^{3-}$ rather than $\mathrm{Hpdc}^{2-}$ found in 18. It is quite apparent that the $\mathrm{pH}$ value is an important factor affecting the structure formation during hydrothermal reactions and can serve as a controlling factor in the rational synthesis of novel coordination polymers.

By controlling the $\mathrm{pH}$ value of the reaction [46], the hydrothermal synthesis with alkaline earth salts [47] or their hydroxides with the $\mathrm{H}_{3}$ pdc ligand gave several new coordination polymers exhibiting different dimensionality. To yield compound $\left[\mathrm{Ca}(\mathrm{Hpdc})\left(\mathrm{H}_{2} \mathrm{O}\right)_{4}\right] \cdot 2 \mathrm{H}_{2} \mathrm{O}$ (20) [48], a mixture of $\mathrm{CaCl}_{2}(0.2 \mathrm{mmol}), \mathrm{H}_{3}$ pdc $(0.1 \mathrm{mmol})$ and deionized water $(10 \mathrm{~mL})$ was heated in a Teflon-lined bomb at $150{ }^{\circ} \mathrm{C}$ for $3 \mathrm{~d}$. After evaporating the resultant colorless solution $(\mathrm{pH}=2.5)$, colorless polyhedral crystals were collected by filtration and washing $(68 \%$ yield). $\left[\mathrm{Ca}(\mathrm{Hpdc})\left(\mathrm{H}_{2} \mathrm{O}\right)_{4}\right] \cdot \mathrm{H}_{2} \mathrm{O}$ (21) was similarly obtained by evaporating the hydrothermal reaction solution $(\mathrm{pH}=5.0)$ of $\mathrm{CaCl}_{2}(0.2 \mathrm{mmol}), \mathrm{H}_{3} \mathrm{pdc}$ $(0.1 \mathrm{mmol}), \mathrm{Et}_{3} \mathrm{~N}(0.2 \mathrm{mmol})$, and water $(10 \mathrm{~mL})$ at $150{ }^{\circ} \mathrm{C}$ for $3 \mathrm{~d}$. Compounds 20 and 21 have onedimensional structures consisting of infinite zigzag 


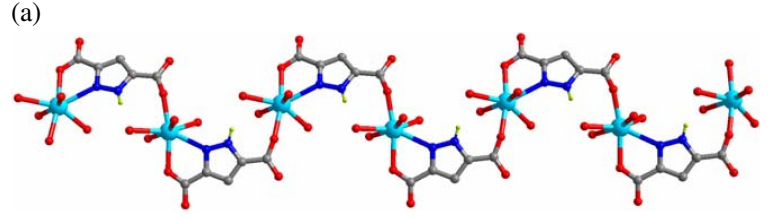

(b)

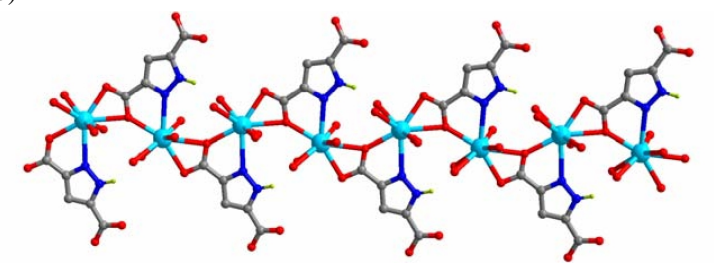

Fig. 9 (color online). One-dimensional chains in compounds 20 (a) and 21 (b). Ca (turquoise), O (red), N (blue), C (gray) and $\mathrm{H}$ (lime).

(a)

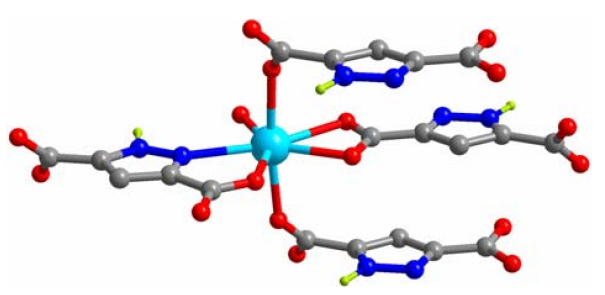

(b)

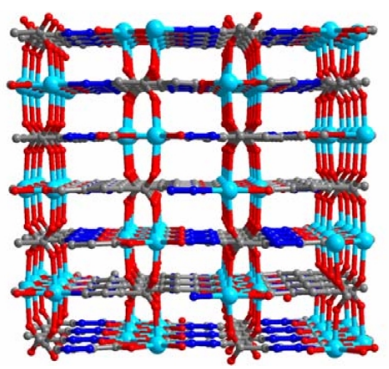

Fig. 10 (color online). View of the coordination environment (a) and the three-dimensional framework (b) of compound 22. $\mathrm{Ca}$ (turquoise), $\mathrm{O}$ (red), $\mathrm{N}$ (blue), $\mathrm{C}$ (gray) and $\mathrm{H}$ (lime).

chains constructed by tetra-aqua-calcium units and bridging $\mathrm{Hpdc}^{2-}$ ligands (Fig. 9). A hydrothermal reaction of $\mathrm{CaCl}_{2}(0.2 \mathrm{mmol}), \mathrm{H}_{3}$ pdc $(0.1 \mathrm{mmol})$ and $\mathrm{Et}_{3} \mathrm{~N}(0.4 \mathrm{mmol})$ in $10 \mathrm{~mL} \mathrm{H}_{2} \mathrm{O}(\mathrm{pH}=9.0)$ at $150{ }^{\circ} \mathrm{C}$ for $3 \mathrm{~d}$ gave colorless column-like crystals of $\left[\mathrm{Ca}(\mathrm{Hpdc})\left(\mathrm{H}_{2} \mathrm{O}\right)\right](\mathbf{2 2})$ (86\% yield). Using $\mathrm{Ca}(\mathrm{OH})_{2}$ (0.5 mmol) in place of $\mathrm{CaCl}_{2}$, the reaction with $\mathrm{H}_{3} \mathrm{pdc}$ $(0.5 \mathrm{mmol})$ in $10 \mathrm{~mL} \mathrm{H}_{2} \mathrm{O}(\mathrm{pH}=11.5)$ under the same experimental conditions (except $\mathrm{pH}$ ) can also produce compound 22. Different from compounds 20 and 21, 22 exhibits a three-dimensional structure and is isostructural to the aforementioned compound 18 (Fig. 10). A comparison of the structures of $\mathbf{2 0}$,
21 with 22 reveals that the connectivity numbers of the ligands in these compounds increase from $\mu_{3}$ and $\mu_{4}$, up to $\mu_{6}$, consistent with the increasing degree of deprotonation of the ligands with the higher $\mathrm{pH}$ of the corresponding reaction mixtures.

Alkaline earth metals with a larger radius were also investigated. The strontium and barium compounds $\left[\mathrm{Sr}(\mathrm{Hpdc})\left(\mathrm{H}_{2} \mathrm{O}\right)\right](\mathbf{2 3}),\left[\mathrm{Ba}\left(\mathrm{H}_{2} \mathrm{pdc}\right)_{2}\left(\mathrm{H}_{2} \mathrm{O}\right)\right] \cdot 2 \mathrm{H}_{2} \mathrm{O}(\mathbf{2 4})$ and $\left[\mathrm{Ba}(\mathrm{Hpdc})\left(\mathrm{H}_{2} \mathrm{O}\right)\right](\mathbf{2 5})$ were prepared by adopting similar hydrothermal reaction procedures as for $\mathbf{2 0 - 2 2}$

(a)

(b)
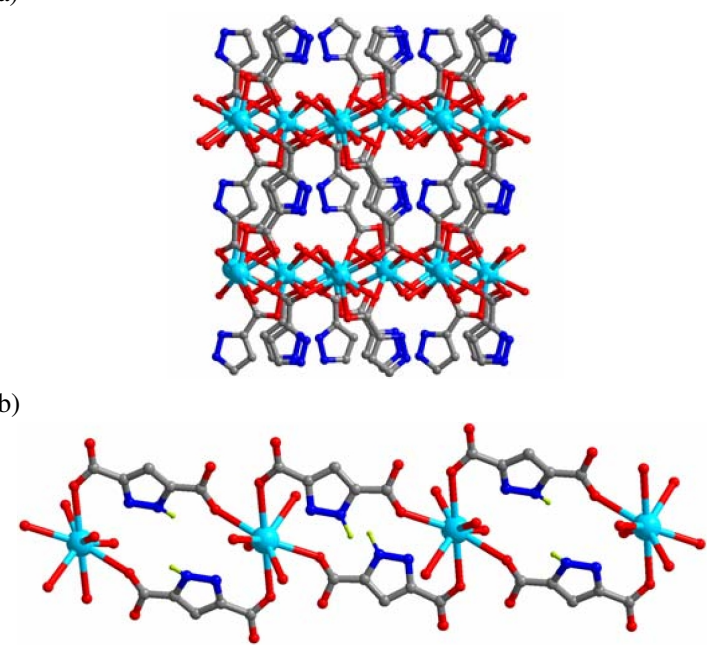

(c)

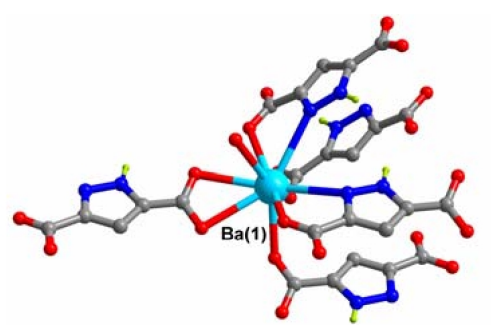

(d)

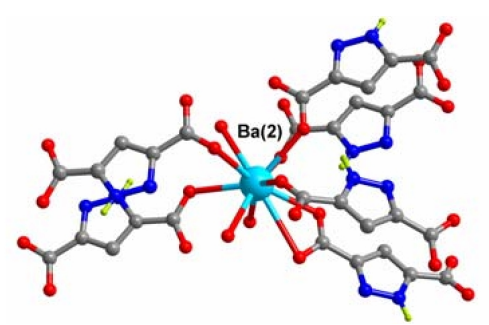

Fig. 11 (color online). a) View of the three-dimensional structure of compound $\mathbf{2 3}$ along the $c$ axis; b) one-dimensional ribbon in compound 24 ; c) and d) view of the coordination geometry of the two crystallographically independent barium sites in compound 25. Sr/Ba (turquoise), O (red), N (blue), C (gray) and $\mathrm{H}$ (lime). 
but at different $\mathrm{pH}$ values. A study on compounds $\mathbf{2 3 -}$ 25 (Fig. 11) has revealed similar trends in the connectivity numbers of the ligands, as well as in the resultant dimensionality of the structures. The same studies on alkaline earth metals have also shown that at lower $\mathrm{pH}$ values the metals tend to coordinate to water molecules, correspondingly limiting their ability to form structures with higher dimensionality.

It is a general observation in the aforementioned investigations on rare-earth, transition, post-transition, and alkaline earth metals that the acidity of the reaction media plays a crucial role in the structure formation under hydrothermal conditions. Increasing $\mathrm{pH}$ leads to higher connectivity of the ligands, and correspondingly to the formation of structures of higher dimensionality.

When pyridine is introduced into the reaction, competition with water in coordination to metal centers is often observed [49]. The one-dimensional chains of compound $\left[\mathrm{Co}(\mathrm{bpdc})\left(\mathrm{H}_{2} \mathrm{O}\right)_{2}\right](\mathbf{2 6})(\mathrm{bpdc}=$

(a)

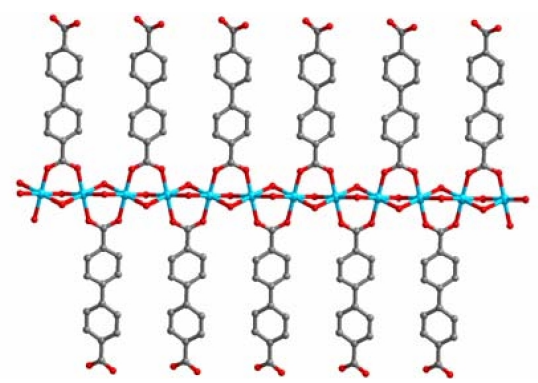

(b)

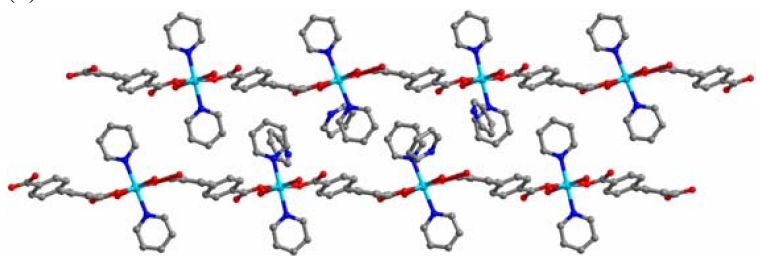

(c)

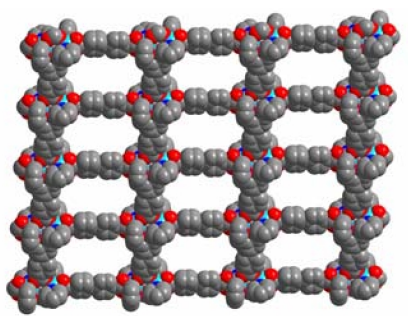

Fig. 12 (color online). a) View of a single chain extending along the $c$ axis in 26; b) the stacking pattern of the single chains in 27 ; c) space-filling model of the noninterpenetrating two-dimensional network of compound $\mathbf{2 8}$ Co (turquoise), O (red), N (blue) and C (gray). biphenyldicarboxylate) can be easily obtained by the reaction of $\mathrm{Co}\left(\mathrm{NO}_{3}\right)_{2}$ and $\mathrm{Na}_{2}$ (bpdc) in aqueous solution [50]. The $\mathrm{Co}^{\mathrm{II}}$ ions in compound $\mathbf{2 6}$ are bridged by four $\mu_{2}-\mathrm{H}_{2} \mathrm{O}$ and two trans $\mu_{2}$-bpdc ligands to form 1D chains along the $c$ axis (Fig. 12a). Starting from this precursor, several structural transformations are observed in mild chemical reactions. When compound 26 was immersed into a pyridine/water $(2: 1)$ solution, single crystals of $\left[\mathrm{Co}(\mathrm{bpdc})(\mathrm{py})_{2}\left(\mathrm{H}_{2} \mathrm{O}\right)_{2}\right]$. 2 py (27) formed very quickly. Compound 27 also exhibits a one-dimensional chain structure, in which the $\mathrm{Co}^{\mathrm{II}}$ ions are bonded to two $\mu_{2}$-bpdc via monodentate carboxylic oxygen atoms, but has two terminal water and two pyridine molecules (Fig. 12b). Hydrogen bonds are found between the hydrogen atoms of coordinated water molecules and uncoordinated carboxylic oxygen atoms. The reaction of $\mathrm{Co}\left(\mathrm{NO}_{3}\right)_{2}(0.5 \mathrm{mmol})$ and $\mathrm{H}_{2}$ bpdc $(0.25 \mathrm{mmol})$ in pyridine/water ( $\left.\mathrm{v}: \mathrm{v}, 1: 1\right)$ solution in a digestion bomb at $120{ }^{\circ} \mathrm{C}$ for $3 \mathrm{~d}$ gave single crystals of the compound $\left[\mathrm{Co}(\mathrm{bpdc})(\mathrm{py})_{2}\right] \cdot \mathrm{H}_{2} \mathrm{O}$ (28). Compound 28 features a non-interpenetrating two-dimensional network, which is constructed by $\mathrm{Co}^{\mathrm{II}}$ ions being interconnected through chelating and bridging monodentate and bidentate bpdc $^{2-}$ ligands (Fig. 12c). Compound $\mathbf{2 6}$ can also be obtained by immersion of compounds $\mathbf{2 7}$ or $\mathbf{2 8}$ in water, suggesting that interconversion between seemingly unrelated structures can occur under mild conditions.

A similar structural transformation phenomenon is also observed in rare earth coordination polymers [51]. The reaction of hydrated $\mathrm{Er}\left(\mathrm{NO}_{3}\right)_{3}(0.075 \mathrm{~g}), \mathrm{H}_{2}$ bdc $(0.036 \mathrm{~g})\left(\mathrm{H}_{2}\right.$ bdc $=$ terephthalic acid $)$ in $\mathrm{H}_{2} \mathrm{O}(10 \mathrm{~mL})$ and $\mathrm{EtOH}(1 \mathrm{~mL})$ mixed solvent was carried out in a $23 \mathrm{~mL}$ acid digestion bomb at $160{ }^{\circ} \mathrm{C}$ for $3 \mathrm{~d}$ to

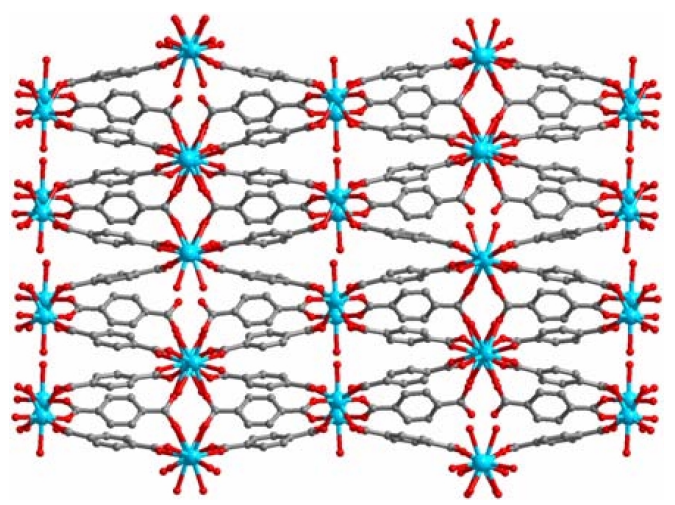

Fig. 13 (color online). Perspective view of the crystal structure of 29 along the $a$ axis. Er (turquoise), $\mathrm{O}$ (red) and $\mathrm{C}$ (gray). 
yield $\left[\mathrm{Er}_{4}(\mathrm{bdc})_{6}\right] \cdot 6 \mathrm{H}_{2} \mathrm{O}(29)$ as pink crystals. Treating a sample of $\mathbf{2 9}$ by first heating at $300{ }^{\circ} \mathrm{C}$ under nitrogen gas, followed by exposure to saturated water vapor for $2 \mathrm{~h}$, gave compound $\left[\mathrm{Er}_{2}(\mathrm{bdc})_{3}\right] \cdot 4 \mathrm{H}_{2} \mathrm{O}(\mathbf{3 0})$, which is isostructural to $\left[\mathrm{Tb}_{2}(\mathrm{bdc})_{3}\right] \cdot 4 \mathrm{H}_{2} \mathrm{O}$ reported by Yaghi et al. [42]. Compounds 29 and 30 both feature condensed three-dimensional network structures. Three types of coordination polyhedra are found for $\mathrm{Er}^{\mathrm{III}}$ ions in compound 29 (Fig. 13). However, in compound $\mathbf{3 0}$ only a single type of dodecahedral coordination geometry is adopted by the $\mathrm{Er}^{\mathrm{III}}$ ions.

Two isomorphic phases of the one-dimensional compounds $\left[\alpha-\mathrm{ZnCl}_{2}\right.$ (bpy)] (31) and $\left[\beta-\mathrm{ZnCl}_{2}\right.$ (bpy)] (32) were assembled by a hydrothermal synthetic method [52]. Compound 31 was prepared by the reactions of $\mathrm{ZnCl}_{2}$ (1 mmol), bpy (bipyridine, $1 \mathrm{mmol}$ ) and $\mathrm{H}_{2} \mathrm{O}(2 \mathrm{~mL})$ in a Teflon-lined autoclave at $170{ }^{\circ} \mathrm{C}$ for $4 \mathrm{~d}$. Using different stoichiometry of the same reactants with reduced concentrations $\left(\mathrm{ZnCl}_{2} 0.1 \mathrm{mmol}\right.$, bpy $0.3 \mathrm{mmol}, \mathrm{H}_{2} \mathrm{O} 8 \mathrm{~mL}$ ) gave compound 32. Onedimensional zigzag chains are found in the structures of $\mathbf{3 1}$ and 32. $\mathrm{Zn}^{\mathrm{II}}$ ions feature tetrahedral geometry that involves two bridging bpy ligands and two terminal chloride ions (Fig. 14). The main difference between the two structures is that one mirror plane passes through the $\mathrm{Zn}$ and $\mathrm{N}$ atoms in compound 32 while a 2 -fold axis exists at the $\mathrm{Zn}$ atoms in compound 31 .

(a)

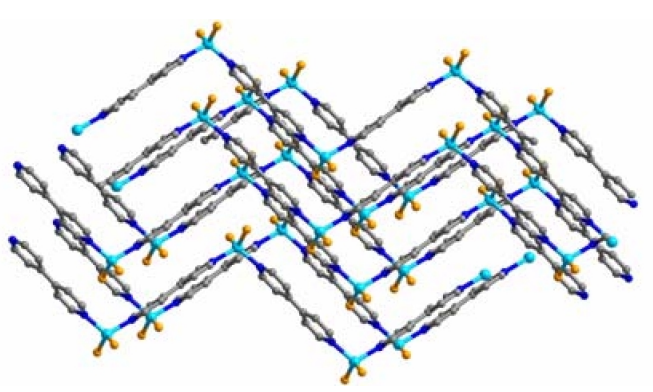

(b)

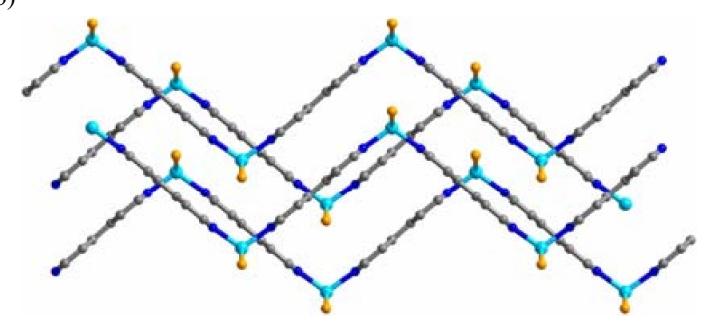

Fig. 14 (color online). View of the zigzag chains in a) $\alpha$ $\mathrm{ZnCl}_{2}$ (bpy) (31) and b) $\beta-\mathrm{ZnCl}_{2}$ (bpy) (32). $\mathrm{Zn}$ (turquoise), $\mathrm{Cl}$ (orange), $\mathrm{N}$ (blue) and $\mathrm{C}$ (gray). (a)

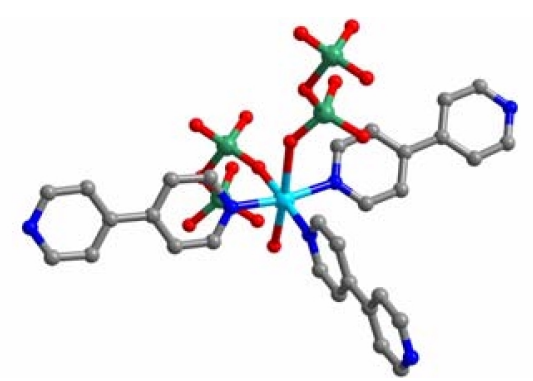

(b)

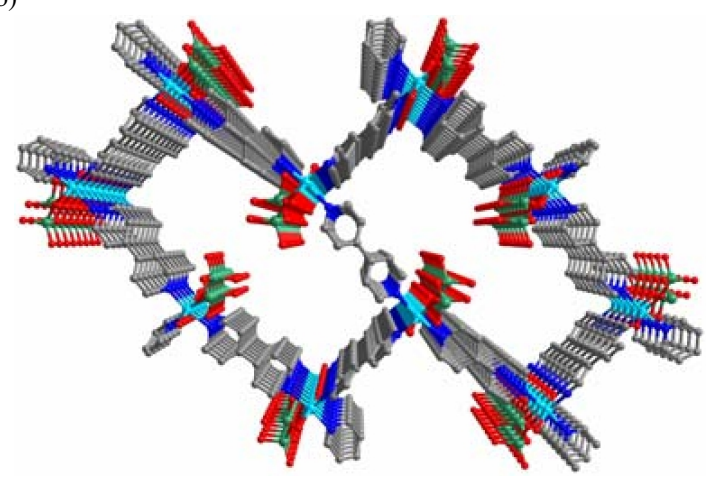

Fig. 15 (color online). View of a) the coordination environment around the $\mathrm{Cu}^{\mathrm{II}}$ sites, and b) the $4^{6} 6^{4} 3 \mathrm{D}$ network found in compound 33. $\mathrm{Cu}$ (turquoise), $\mathrm{Cr}$ (green), $\mathrm{O}$ (red), $\mathrm{N}$ (blue) and $\mathrm{C}$ (gray).

In compound $\left[\mathrm{Cu}(\text { bpy })_{1.5}\left(\mathrm{Cr}_{2} \mathrm{O}_{7}\right)\right] \cdot \mathrm{H}_{2} \mathrm{O}(\mathbf{3 3})$, the $\mathrm{Cr}_{2} \mathrm{O}_{7}{ }^{2-}$ anion was found acting as an effective secondary ligand to bridge $\mathrm{Cu}$ centers in a 3D structure [53]. Compound $\mathbf{3 3}$ was synthesized in a hydrothermal reaction of $\mathrm{Cu}\left(\mathrm{NO}_{3}\right)_{2} \cdot 3 \mathrm{H}_{2} \mathrm{O}$, bpy, $\mathrm{K}_{2} \mathrm{Cr}_{2} \mathrm{O}_{7}$ and $\mathrm{H}_{2} \mathrm{O}$ in the ratio of $1: 1: 0.5: 5555$ at $150{ }^{\circ} \mathrm{C}$ for $3 \mathrm{~d}$. In the structure, $\mathrm{Cu}$ centers are all six-coordinated to three nitrogen atoms from three bpy ligands, two oxygen atoms from two $\mathrm{Cr}_{2} \mathrm{O}_{7}{ }^{2-}$ anions and an oxygen atom from a water molecule (Fig. 15). $\mathrm{Cu}$ atoms are connected with bpy ligands to form a 2D Cu-bpy network, which is further extended to a unique 3D structure having $4^{6} 6^{4}$ topology by the bonding between the $\mathrm{Cu}$ centers and the $\mathrm{Cr}_{2} \mathrm{O}_{7}{ }^{2-}$ anions. Large 1D channels are found along the $a$ axis with a cross-section of the windows measured as $11.2 \times$ $22.0 \AA^{2}$. Two identical networks are also found interlocking in the structure to present two-fold interpenetration, avoiding the formation of large open space.

Hydrogen-bonded three-dimensional networks $\left[M\left(\mathrm{H}_{2} \mathrm{pdc}\right)_{2}\left(\mathrm{H}_{2} \mathrm{O}\right)_{2}\right] \cdot 2 \mathrm{H}_{2} \mathrm{O}(M=\mathrm{Mn}, \mathrm{Fe}, \mathrm{Co}, \mathrm{Ni}, \mathrm{Zn})$ were also prepared by hydrothermal reactions [54]. In a typical procedure, heating of $\mathrm{Co}\left(\mathrm{NO}_{3}\right)_{2} \cdot 6 \mathrm{H}_{2} \mathrm{O}$ 
(a)

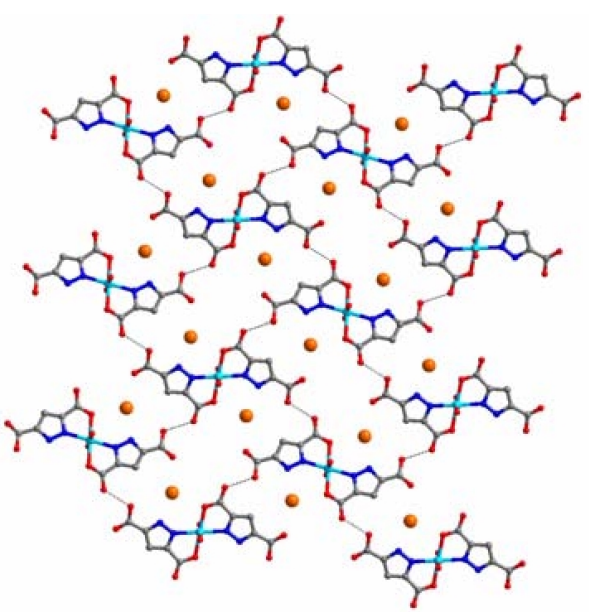

(b)

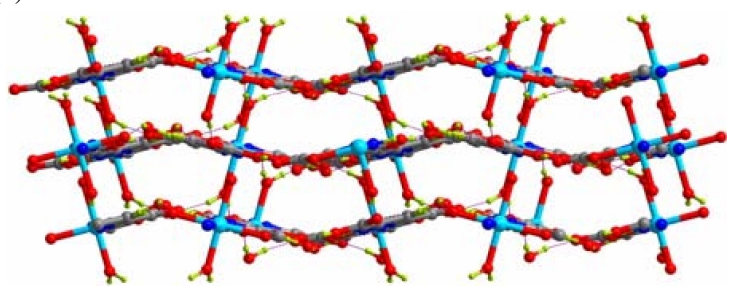

Fig. 16 (color online). a) View of the basket-weave-like, two-dimensional hydrogen-bonded network in compound $\mathbf{3 4}$ (the large yellow balls represent the two water molecules); b) view of the hydrogen-bonded 3D network of compound 34. Co (turquoise), O (red), $\mathrm{N}$ (blue), $\mathrm{C}$ (gray) and $\mathrm{H}$ (lime).

(0.25 mmol) and $\mathrm{H}_{3}$ pdc $(0.5 \mathrm{mmol})$ in $10 \mathrm{~mL} \mathrm{H}_{2} \mathrm{O}$ $(\mathrm{pH}=1.5)$ at $150{ }^{\circ} \mathrm{C}$ for $3 \mathrm{~d}$ gave beige column-like crystals of $\left[\mathrm{Co}\left(\mathrm{H}_{2} \mathrm{pdc}\right)_{2}\left(\mathrm{H}_{2} \mathrm{O}\right)_{2}\right] \cdot 2 \mathrm{H}_{2} \mathrm{O}(34)$. In compound 34, each $\mathrm{Co}^{\mathrm{II}}$ ion is six-coordinated to two sets of oxygen and adjacent pyrazole nitrogen atoms from two separate $\mathrm{H}_{2} \mathrm{pdc}^{-}$ligands and two $\mathrm{H}_{2} \mathrm{O}$ molecules. Basket-weave-like 2D networks are found through strong hydrogen bonds between two neighboring $\mathrm{H}_{2} \mathrm{pdc}^{-}$ions in compound 34 (Fig. 16). Adjacent layers are further interconnected through hydrogen bonding between the coordinated water molecules and the 3,5-pyrazoledicarboxylate ions. Upon heating of these hydrogen-bonded compounds, all four water molecules in the structures can be removed. This process is accompanied with distinct color changes. After re-immersing the formed amorphous samples in water the original 3D structure can be recovered. Such a reversible structural interconversion process can be explained by breakage and reformation of the hydrogen bonding network. Dissolution of dehydrated $34(6 \mathrm{mg})$ in methanol $(3 \mathrm{~mL})$ leads to the (a)

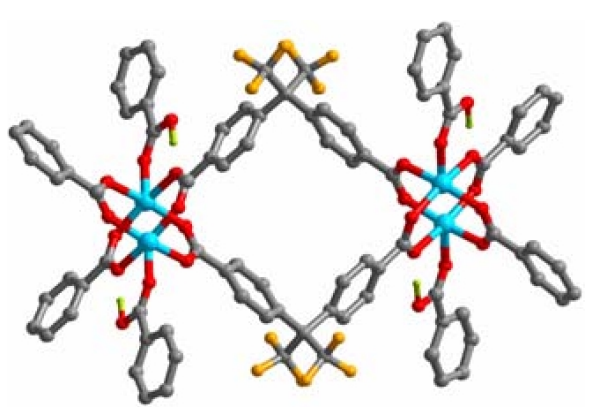

(b)

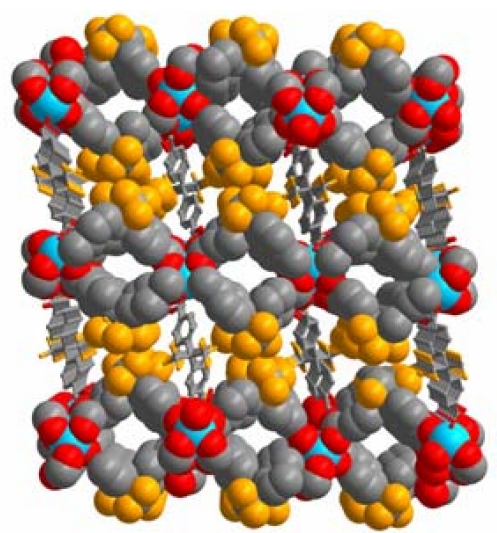

Fig. 17 (color online). a) Secondary building unit and cross section of a single microtube, and $b$ ) the three-dimensional packing of 36. Cu (turquoise), O (red), C (gray), F (orange) and $\mathrm{H}$ (lime).

transformation to another supramolecular compound $\left[\mathrm{Co}_{4}(\mathrm{Hpdc})_{4}(\mathrm{py})_{12}\right]$ (35) upon addition of pyridine (2 mL).

The microporous metal-organic framework $[\mathrm{Cu}-$ (hfipbb) $\left(\mathrm{H}_{2} \mathrm{hfipbb}\right)_{0.5}$ ] (36) was prepared by hydrothermal reaction of $\mathrm{Cu}\left(\mathrm{NO}_{3}\right)_{2} \cdot 3 \mathrm{H}_{2} \mathrm{O}(0.12 \mathrm{mmol})$ and $\mathrm{H}_{2}$ hfipbb $(0.5 \mathrm{mmol})\left(\mathrm{H}_{2}\right.$ hfipbb $=4,4^{\prime}$-(hexafluoroisopropylidene)-bis(benzoic acid)) in $5 \mathrm{~mL}$ water at $125{ }^{\circ} \mathrm{C}$ for $3 \mathrm{~d}$ [55]. Blue column-like crystals of compound 36 were collected after washing (DMF, $10 \mathrm{~mL} \times 3)$ and vacuum drying $(92 \%$ yield $)$. The three-dimensional structure of compound 36 (Fig. 17) is built upon paddle-wheel-like di-copper secondary building units (SBUs), which are formed by two $\mathrm{Cu}$ (II) ions sharing four carboxylate groups from four hfipbb $^{2-}$ ligands ( $\mathrm{Cu}-\mathrm{Cu}$ distance: $2.645 \AA$ ). These SBUs are interconnected by hfipbb ligands to form an ondulating 2D network with $4^{4}$ topology. Further interconnection of adjacent 2D layers through the binding of monodentate $\mathrm{H}_{2}$ hfipbb ligands to apical positions of the di-cooper paddle-wheels give the three- 
(a)

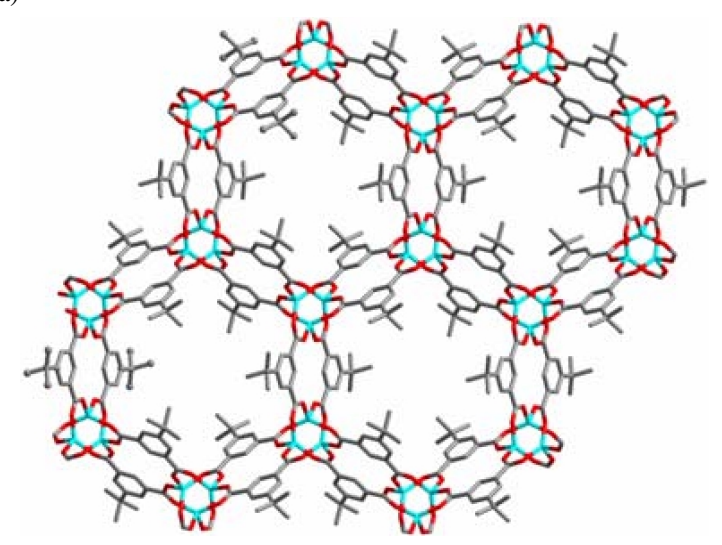

(b)

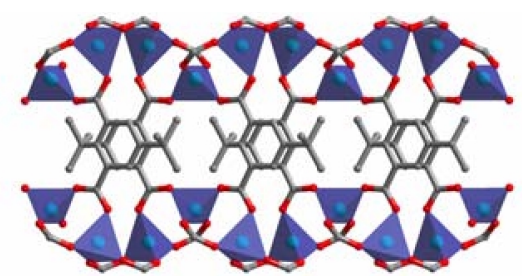

Fig. 18 (color online). a) Crystal structure of $\mathbf{3 7}$ showing the hexagonal close-packed 1D open channels along the $c$ axis; b) view of the channel wall $\left(\mathrm{ZnO}_{4}\right.$ shown as a polyhedron). $\mathrm{Zn}$ (turquoise), $\mathrm{O}$ (red) and $\mathrm{C}$ (gray).

dimensional framework. A two-fold interpenetration is found in the structure, resulting in small microchannels $\left(\sim 3.5 \times 3.5 \AA^{2}\right.$, excluding the van de Waals radius of carbon) and larger cages $\left(\sim 5.1 \times 5.1 \AA^{2}\right)$ inside. TGA measurement has shown a guest-free framework for compound 36, and a solvent-accessible volume of $11.6 \%$ has been calculated by PLATON.

Compound [Zn(tbip)] (37) (tbip = 5-tert-butyl isophthalate) is another guest-free microporous coordination metal-organic framework [56]. 37 was synthesized by hydrothermal reaction of a mixture of $\mathrm{Zn}\left(\mathrm{NO}_{3}\right)_{2} \cdot 6 \mathrm{H}_{2} \mathrm{O}(0.66 \mathrm{mmol}), \mathrm{H}_{2}$ tbip (0.66 mmol), $\mathrm{H}_{2} \mathrm{O}(13 \mathrm{~mL})$ and ethylene glycol $(3 \mathrm{~mL})$ at $180{ }^{\circ} \mathrm{C}$ for $3 \mathrm{~d}$. In the structure, $\mathrm{Zn}^{\mathrm{II}}$ centers adopt tetrahedral coordination geometry by linking four tbip ${ }^{2-}$ ligands (Fig. 18a). Adjacent zinc nodes are bridged by two carboxylate groups to generate a 31 helical chain with a pitch of $7.977 \AA$ along the crystallographic $c$ axis. Neighboring chains are interconnected through tbip ${ }^{2-}$ ligands with the closest interchain distance of $7.212 \AA$, resulting in a $3 \mathrm{D}$ structure possessing hexagonal closepacked 1D open channels along the $c$ axis. The diameter of the channel is reduced to $4.5 \AA$ (excluding the van der Waals radius of hydrogen) due to the methyl groups protruding into the channel. Strong $\pi-\pi$ interactions via a slipped $\pi$-stacking mode are found between the phenyl rings that form the channel walls (Fig. 18b). Compared with compound 36, a larger freely accessible volume of $17.7 \%$ of compound 37 is calculated by PLATON, which can be attributed to a more effective packing.

\section{Solvothermal reactions in non-aqueous solvents}

As widely as hydrothermal reactions have been used in the preparation of coordination network materials, non-aqueous solvents have also been commonly employed in the synthesis of MOF compounds. $N, N^{\prime}$ Dimethylformamide (DMF) is one of the most common organic solvents used in these reactions due to its very good solubilizing capability for both the organic ligands and the inorganic metal salts.

Coordination networks containing multiporphyrin groups are particularly interesting due to their special electron distribution characters [57]. To construct a metalloporphyrin structure, a solvothermal synthesis strategy was used to improve the solubility of the free-base meso-tetra(4-pyridyl)porphyrin $\left(\mathrm{H}_{2} \mathrm{TPyP}\right)$ ligand [58]. Heating a DMF (3 mL) solution of ferrocene $(0.54 \mathrm{mmol})$ and $\mathrm{H}_{2} \mathrm{TPyP}(0.24 \mathrm{mmol})$ in a Teflon-lined bomb at $150{ }^{\circ} \mathrm{C}$ for $5 \mathrm{~d}$ and washing the product with ethanol and diethyl ether gave two phases having the same composition: the main phase being the dark-red cubic crystals of $\alpha$-[Fe(TPyP)] (38) (Fig. 19) and a minor phase being the red plate-like crystals of $\beta$-[Fe(TpyP)] (39). The $\mathrm{Fe}^{\mathrm{II}}$ ions in both compounds are six coordinated with four $\mathrm{N}$ atoms from pyrrole moieties of the porphyrin ligand at equatorial

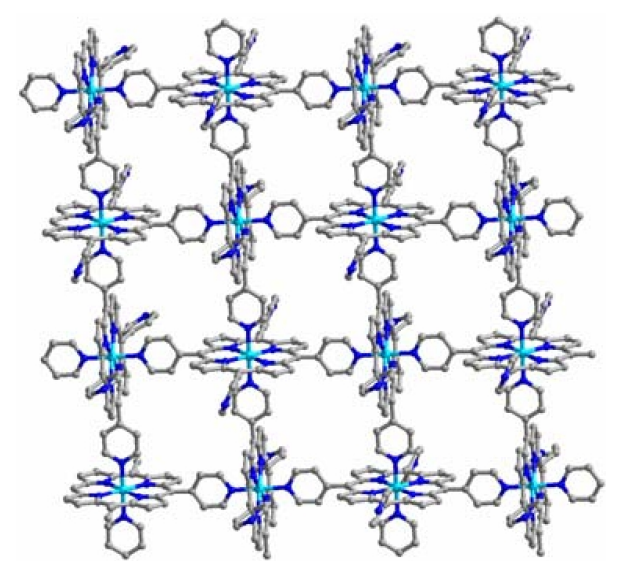

Fig. 19 (color online). View of the 2D structure of compound 38 along the $a$ axis. Fe (turquoise), N (blue) and C (gray). 


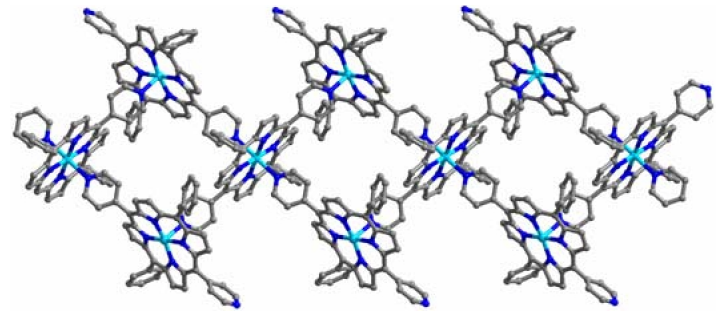

Fig. 20 (color online). View of the 1D coordination array in compound 40. Co (turquoise), N (blue) and C (gray).

positions, and two pyridine $\mathrm{N}$ atoms from two adjacent porphyrin molecules at the two axial positions. Such a coordination configuration results in a twodimensional paddle-wheel-like pattern with all neighboring porphyrin molecules mutually perpendicular. Single crystal analyses of compounds 38 and 39 revealed the different packing sequences: $\cdots$ ABAB $\cdots$ in 38 and $\cdots$ ABCDABCD $\cdots$ in 39.

Another $1 \mathrm{D}$ metalloporphyrin polymer $\mathrm{CCO}_{3}$ $\left.(\mathrm{DPyP})_{3}\right] \cdot$ 4DMF (40) was produced by using a trans meso-bifunctional porphyrin, 5,25-dipyridyl-10,20diphenylporphyrin $\left(\mathrm{H}_{2} \mathrm{DPyP}\right)$ [59]. Pink crystals of compound 40 were crystallized by solvothermal reactions of $\mathrm{Co}\left(\mathrm{NO}_{3}\right)_{2}$ with $\mathrm{H}_{2} \mathrm{DPyP}$ in DMF at $130{ }^{\circ} \mathrm{C}$. Structure analysis of compound $\mathbf{4 0}$ revealed a novel 1D infinite array of tetranuclear metalloporphyrin cages adjoined by the coordination of pyridyl nitrogen atoms to $\mathrm{Co}$ (II) (Fig. 20). There are two types of the metalloporphyrin found in the network, occupying the node and corner positions of the cages, respectively. The $\operatorname{Co}(\mathrm{II})$ ions in the nodal porphyrin ligands are six-coordinated while those in the porphyrin ligands occupying the corner positions are five-coordinated.

Porous three-dimensional materials, especially those having recyclable framework structures, are highly desirable due to their great potential in gas storage, separation and catalytic applications. The closely related $3 \mathrm{D}$ frameworks $\left[M_{3}(\mathrm{bpdc})_{3}\right.$ (bpy)] $\cdot 4 \mathrm{DMF} \cdot \mathrm{H}_{2} \mathrm{O} \mathbf{4 1}(\mathrm{Co})$ and 42 (Zn) $[60,61]$ were prepared from a nonporous $1 \mathrm{D}$ precursor $[M(\mathrm{bpdc})$ $\left.\left(\mathrm{H}_{2} \mathrm{O}\right)_{2}\right] \cdot \mathrm{H}_{2} \mathrm{O}(M=\mathrm{Co}, \mathrm{Zn})$ (the aforementioned 26). In a typical reaction, a mixture of compound 26 $(0.3 \mathrm{mmol})$ and bpy $(0.1 \mathrm{mmol})$ in DMF $(10 \mathrm{~mL})$, sealed in a Teflon-lined bomb and heated at $150{ }^{\circ} \mathrm{C}$ for $3 \mathrm{~d}$, gave rise to deep-purple columnar crystals of compound $\mathbf{4 1}$ (95\% yield). $\mathbf{4 1}$ can also be obtained by the solvothermal reaction of $\mathrm{Co}\left(\mathrm{NO}_{3}\right)_{2}, \mathrm{H}_{2}$ bpdc and bpy ligand in DMF at $150{ }^{\circ} \mathrm{C}$ for $3 \mathrm{~d}$. The structure of compound 41 (Fig. 21) features unique (a)

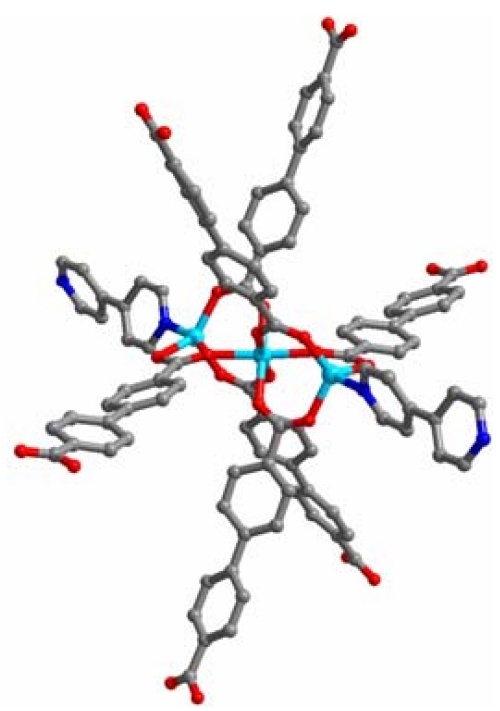

(b)

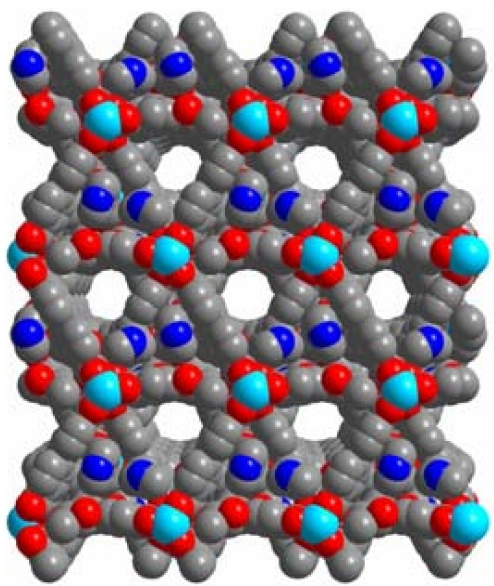

Fig. 21 (color online). The $\left[\mathrm{Co}_{3}(\mathrm{bpdc})_{6}(\mathrm{bpy})_{2}\right]$ building unit (a) and the side view of the one-dimensional channels (b) in 41. Co (turquoise), O (red), $\mathrm{N}$ (blue) and $\mathrm{C}$ (gray).

tri-nuclear SBUs, $\left[\mathrm{Co}_{3}(\mathrm{COO})_{6}\right]$, which contain two crystallographically independent cobalt centers. The octahedrally coordinated Col center is located on the two-fold rotational axis, and the two adjacent $\mathrm{Co} 2$ centers adopt a distorted trigonal bipyramidal geometry. Each of the $\mathrm{Co} 1-\mathrm{Co} 2$ pairs is connected by two $\mu_{2}$ and one $\mu_{3}$ oxygen atoms from three carboxylate groups. Adjacent $\left[\mathrm{Co}_{3}(\mathrm{COO})_{6}\right]$ SBUs, which act as nodes in the structure of compound $\mathbf{4 1}$, are interconnected through six bpdc ${ }^{2-}$ ligands to form a 2D layer in the $a b$ plane. Adjacent layers are interconnected by bpy as pillaring ligands coordinating to the terminal $\mathrm{Co} 2$ centers to generate a $3 \mathrm{D}$ framework. 
Two-fold interpenetration of such networks completes the structure of 41. Structure analysis also reveals 1D channels that can be viewed as large supercages (approximately $11 \times 11 \times 5 \AA^{3}$, excluding the van der Waals radius of the carbon atoms) connected through smaller triangular windows of a maximum effective dimension of about $8 \AA$. The calculated solvent-accessible pore volume of the compound is $42.4 \%$ of the unit cell volume. Studies have shown that the $3 \mathrm{D}$ framework of compound $\mathbf{4 1}$ is readily broken down and converted back to the nonporous 1D precursor 26, and such a structural interconversion is completely reversible.

Similar to $\mathbf{4 1}$, the zinc compound $\mathbf{4 2}$ can also be prepared from the solvothermal reaction of its corresponding 1D precursor and bpy in DMF, or directly from the reaction of $\mathrm{Zn}\left(\mathrm{NO}_{3}\right)_{2}, \mathrm{H}_{2}$ bpdc and bpy in the molar ratio of $1: 1: 1$ in DMF, as colorless columnar crystals. Crystal structure analysis has revealed that the structure of $\mathbf{4 2}$ is closely related to that of $\mathbf{4 1}$ with minor differences. In compound 42, two terminal $\mathrm{Zn}$ centers of the tri-nuclear SBU are tetrahedrally coordinated instead of the five-coordination pattern found in 41. However, this difference in coordination configuration of the $\mathrm{Zn}^{\mathrm{II}}$ ions does not cause striking changes in the overall motifs and topology of the structure. The calculated free volume in $\mathbf{4 2}$ is $\mathbf{4 0 . 7} \%$ of the unit cell volume, slightly lower than in $\mathbf{4 1}$.

By replacing the terminal py with bridging bpy ligands, the 2D network of $\mathbf{2 8}$ can be extended to a new $3 \mathrm{D}$ porous framework $[\mathrm{Co}(\mathrm{bpdc})(\mathrm{bpy})] \cdot 0.5 \mathrm{DMF}(\mathbf{4 3})$ in a solvothermal reaction [62]. 43 was synthesized by heating a mixture of $\mathbf{2 8}$ and bpy in the molar ratio of $1: 4$ in DMF ( $5 \mathrm{~mL})$ at $120{ }^{\circ} \mathrm{C}$ for one day. Orange needle-like crystals of $\mathbf{4 3}$ were obtained in high yield (90\%). Single-crystal X-ray diffraction has revealed that compound $\mathbf{4 3}$ still contains the $2 \mathrm{D}$ motif found in 28 (Fig. 22). The bidentate bpy ligands interconnect the 2D motifs to form a pillared 3D network. Two of these pillared 3D networks, identical in structure, interpenetrate each other to generate an overall structure of 43 with rectangular-shaped $1 \mathrm{D}$ open channels $(\sim 5.6 \times$ $3.0 \AA^{2}$, excluding the van der Waals radius of carbon atoms) along the $a$ axis. DMF molecules are found filling the channels in a head-to-tail fashion, which can be removed upon heating to give $28.6 \%$ free voids in the unit cell volume.

Interpenetration is also found in another luminescent microporous metal-organic framework $\left[\mathrm{Zn}_{2}\right.$ $(\text { bpdc })_{2}($ bpee $\left.)\right] \cdot 2$ DMF (44) (bpee $=1,2$-bipyridyl- (a)

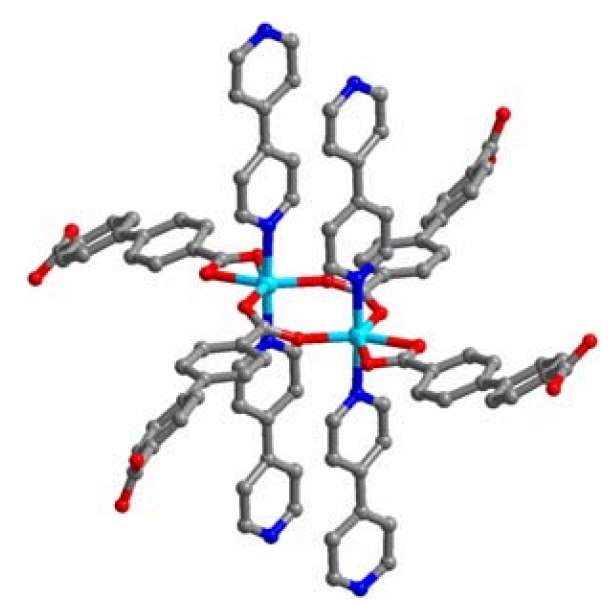

(b)

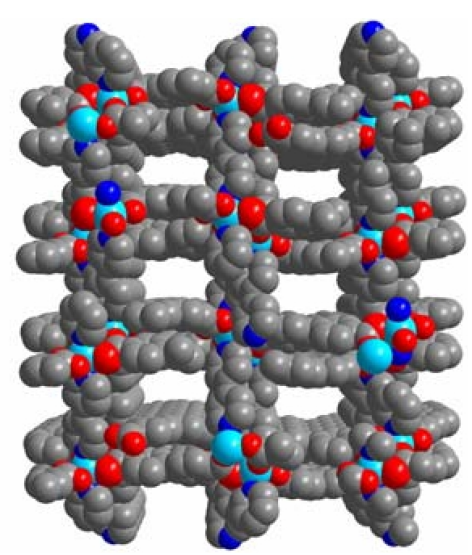

Fig. 22 (color online). The $\left[\mathrm{Co}_{2}(\mathrm{bpdc})_{4}(\mathrm{bpy})_{2}\right]$ building unit (a) and the catenated network with rectangular-shaped 1D channels (b) in 43. Co (turquoise), O (red), N (blue) and C (gray).

ethene) [63]. By reacting a mixture of $\mathrm{Zn}\left(\mathrm{NO}_{3}\right)_{2}$ $(0.3 \mathrm{mmol}), \mathrm{H}_{2}$ bpdc $(0.3 \mathrm{mmol})$ and bpee $(0.3 \mathrm{mmol})$ in DMF $(15 \mathrm{~mL})$ in a Teflon-lined autoclave at $165^{\circ} \mathrm{C}$ for $3 \mathrm{~d}$, colorless block-shaped crystals of $\mathbf{4 4}$ were formed $(58 \%$ yield). The structure of compound 44 contains dinuclear eight-membered ring-type secondary building units (Fig. 23). Each four-connecting node is linked to four other nodes by bpdc ${ }^{2-}$ ligands to form the $2 \mathrm{D} 4^{4}$ (brick-like) net. Two of such identical nets interpenetrate to generate a layer. Bpee ligands are coordinated to two $\mathrm{Zn}$ centers of adjacent layers to satisfy the tetrahedral coordination configuration of each $\mathrm{Zn}$ center, and act as pillars interconnecting the layers to the overall 3D structure. Parallelogram-shaped $1 \mathrm{D}$ open channels run along the $b$ axis with a window size around $5.0 \times 7.0 \AA^{2}$ (excluding the van der Waals 
(a)

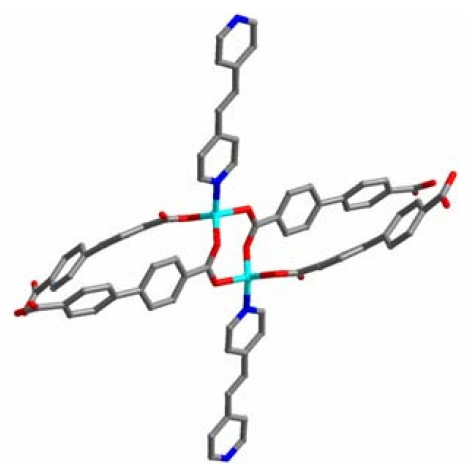

(b)

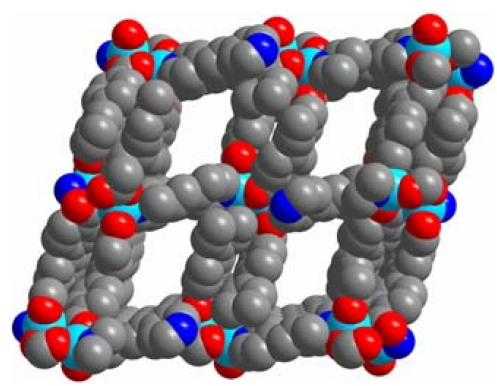

Fig. 23 (color online). The di-zinc secondary building unit (a) and the overall 3D framework (b) of 44. Zn (turquoise), $\mathrm{O}$ (red), $\mathrm{N}$ (blue) and C (gray).

radius of the carbon atoms). $27.6 \%$ of the unit cell volume is calculated as solvent-accessible volume in compound 44.

Applications of porous framework materials, e. $g$. for gas storage and separation, require the sustainment of their structural integrity and porosity after removal of guest molecules. This remains a challenge partly due to the flexibility of extended organic ligands that are commonly employed to induce the formation of highly porous materials. Conversely, employing relatively shorter and more rigid ligands, such as formate, may yield more robust frameworks. Pink block-like single crystals of $\left[\mathrm{Co}_{3}(\mathrm{HCOO})_{6}\right] \cdot \mathrm{DMF}(\mathbf{4 5})$ were obtained by reaction of $\mathrm{Co}\left(\mathrm{NO}_{3}\right)_{2}(1.4 \mathrm{mmol})$ and formic acid $(97 \%, 2.8 \mathrm{mmol})$ in DMF $(20 \mathrm{~mL})$ in a Teflonlined bomb at $100{ }^{\circ} \mathrm{C}$ for $2 \mathrm{~d}$ [64]. An isostructural manganese compound $\left[\mathrm{Mn}_{3}(\mathrm{HCOO})_{6}\right] \cdot \mathrm{DMF}(\mathbf{4 6})$ and a nickel compound $\left[\mathrm{Ni}_{3}(\mathrm{HCOO})_{6}\right] \cdot \mathrm{DMF}(47)$ can also be prepared in a similar way. Compound 45 crystallizes in the monoclinic space group $P 2_{1} / n$. Four crystallographically independent $\mathrm{Co}^{\mathrm{II}}$ centers (the occupation factors of $\mathrm{Co} 3$ and $\mathrm{Co} 4$ are 0.5), six formate anions and one guest DMF molecule are found in the asymmetric unit of structure 45 (Fig. 24). The $\mathrm{Co}^{\mathrm{II}}$ (a)

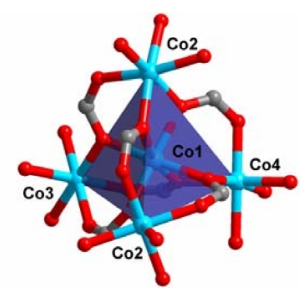

(b)

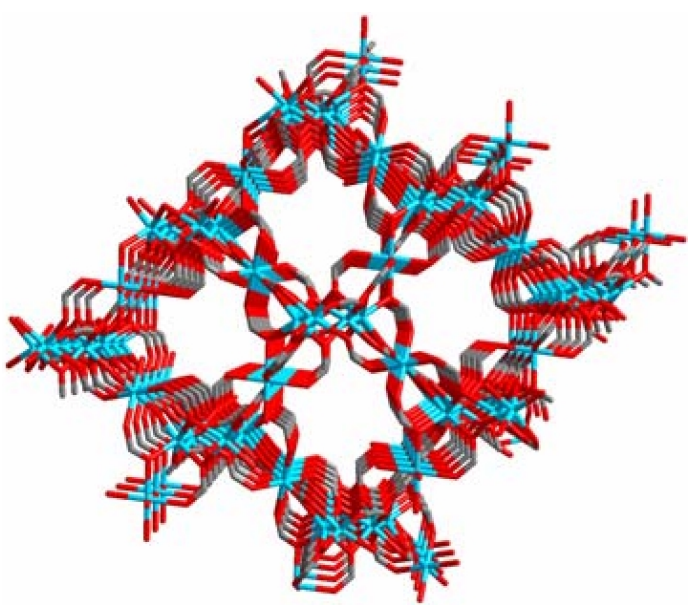

Fig. 24 (color online). The distorted penta-nuclear tetrahedron with Co1 residing in the center (a), and the perspective view of the overall structure of compound $\mathbf{4 5}$ along the $b$ axis, showing the channels (b). Co (turquoise), $\mathrm{O}$ (red) and $\mathrm{C}$ (grey).

centers are all six-coordinated to oxygen atoms from separate formate ligands with distorted octahedral geometry. Among the four different $\mathrm{Co}^{\mathrm{II}}$ centers, $\mathrm{Co} 1$ is located at the center of a distorted tetrahedron formed by $\mathrm{Co} 2, \mathrm{Co} 3, \mathrm{Co} 4$ and another $\mathrm{Co} 2$ atoms at the four apexes. Six formate ligands connect each of the $\mathrm{Co}^{\mathrm{II}}$ centers at the apex in syn/anti mode along the edges of the tetrahedron, with one oxygen atom from each formate ligand also binding to the central Col atom in syn mode. The three-dimensional framework of compound $\mathbf{4 5}$ is built through apex-sharing of these Col-centered $\mathrm{CoCo}_{4}$ tetrahedron, which can be simplified by connecting all tetrahedral nodes into a distorted diamondlike network. One-dimensional zigzag channels $(\sim 5-$ $6 \AA$ in size) filled with DMF guest molecules are observed along the $b$ axis. Based on the calculation of PLATON, 30.9\% of the unit cell volume can be used for other guests upon removal of the DMF.

One implication of using extended organic linkers to induce the formation of highly porous materials is that interpenetration of two or more iden- 


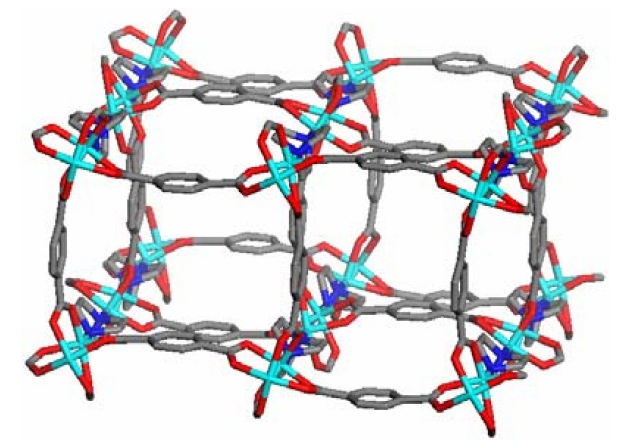

Fig. 25 (color online). View of the framework of compound 48. Zn (turquoise), $\mathrm{O}$ (red), $\mathrm{N}$ (blue) and $\mathrm{C}$ (gray).

tical frameworks often results in low porosity. One possible solution to prevent interpenetration is to use bulky molecular species such as triethylenediamine (ted) [65]. [ $\mathrm{Zn}$ (bdc)(ted) $\left.)_{0.5}\right] \cdot 2 \mathrm{DMF} \cdot 0.2 \mathrm{H}_{2} \mathrm{O}$ (48) was crystallized from a solvothermal reaction mixture of $\mathrm{Zn}\left(\mathrm{NO}_{3}\right)_{2}(0.60 \mathrm{mmol}), \mathrm{H}_{2}$ bdc $(0.61 \mathrm{mmol})$ and ted $(0.32 \mathrm{mmol})$ in $15 \mathrm{~mL}$ of DMF kept at $120{ }^{\circ} \mathrm{C}$ for $2 \mathrm{~d}$ [66]. Colorless block-shaped crystals were isolated after washing with DMF and drying in air ( $83 \%$ yield). The isostructural copper compound $\left[\mathrm{Cu}(\mathrm{bdc})(\text { ted })_{0.5}\right] \cdot 2 \mathrm{DMF} \cdot 0.2 \mathrm{H}_{2} \mathrm{O}(\mathbf{4 9})$ was also prepared under similar conditions. Compound 48 crystallizes in the tetragonal crystal system with space group $P 4 / n c c$. The structure of $\mathbf{4 8}$ consists of paddle-wheel $\mathrm{Zn}_{2}(\mathrm{COO})_{4}(\text { ted })_{2}$ SBUs, which are linked by bdc ligands within the layer to form a 2D net (Fig. 25). The 2D nets are further linked by ted pillars to give rise to a 3D framework with three-dimensionally interconnected pores. The 3D porous structure contains two types of interlacing channels with the window size of the channels along the $c$ axis at around $7.5 \times 7.5 \AA^{2}$ and those along the $a$ or $b$ axes at around $4.8 \times$ $3.2 \AA^{2}$ (excluding the van der Waals radius of the carbon atoms). The free volume calculated by PLATON is $58.4 \%$ of the unit cell volume for $\mathbf{4 8}$.

While aromatic carboxylate ligands are commonly employed in constructing porous coordination framework materials because of their good directionality in coordination and their mechanical rigidity, aliphatic carboxylate ligands are rarely found useful due to the lack of such properties. A few exceptions exist, in which rigid aliphatic ligands are used $[67,68]$. For example, the aliphatic ligand $\mathrm{H}_{2}$ bodc $\left(\mathrm{H}_{2}\right.$ bodc $=$ bicycle[2.2.2] octane-1,4-dicarboxylic acid $)$ and the pillar ligand ted have both been employed in the construction of two new isostructural 3D

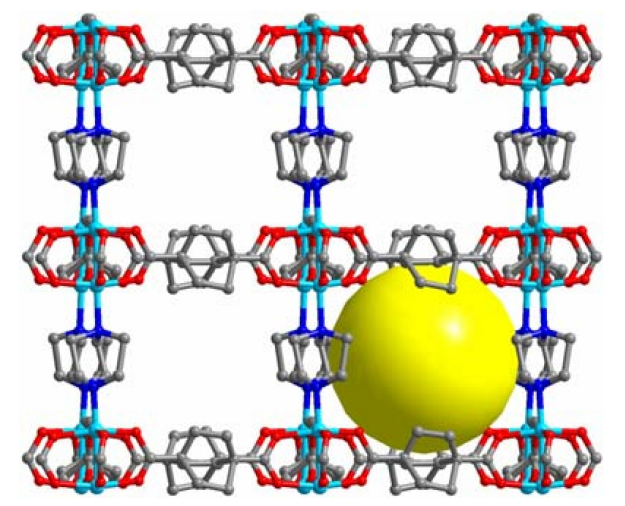

Fig. 26 (color online). The overall 3D structure of $\mathbf{5 1}$ (Co) with one cage being highlighted by the yellow sphere. Zn (turquoise), O (red), N (blue) and C (gray).

non-interpenetrating frameworks, $\left[\mathrm{Ni}(\right.$ bodc $\left.)(\text { ted })_{0.5}\right]$ (50) and $\left[\mathrm{Co}(\text { bodc)(ted) })_{0.5}\right]$ (51) (Fig. 26) [69]. The solvothermal reaction of $\mathrm{Ni}\left(\mathrm{NO}_{3}\right)_{2}$ (or $\left.\mathrm{Co}\left(\mathrm{NO}_{3}\right)_{2}\right)$ (0.64 mmol) with $\mathrm{H}_{2}$ bodc $(0.58 \mathrm{mmol})$ and ted $(1.41 \mathrm{mmol})$ in DMF $\left(20 \mathrm{~mL} / 0.1 \mathrm{~mL}\right.$ conc. $\mathrm{HNO}_{3}$ added) at $100{ }^{\circ} \mathrm{C}$ for $4 \mathrm{~d}$ yielded a crystalline powder of $\mathbf{5 0}$ (or 51) in high yield. Structure analysis has revealed that compound $\mathbf{5 1}$ has a similar pillared layer structure as that of $\mathbf{4 8}$ and consists of paddle-wheellike $\mathrm{Co}(\mathrm{COO})_{4}$ SBUs. Calculation by PLATON shows that the three-dimensionally interconnected pores in $\mathbf{5 1}$ occupy about $49 \%$ of the volume of the structure.

Apart from DMF, other organic solvents, such as methanol, ethanol, butanol, etc., or their mixtures, can also be the solvents of choice for solvothermal reactions. Two novel zeolitic imidazolate frameworks (ZIFs) $[70,71],\left[\mathrm{Zn}(2-\mathrm{cim})_{2}\right] \cdot 2.1 \mathrm{CH}_{3} \mathrm{OH}(\mathbf{5 2})$ and $\left[\mathrm{Zn}(2-\mathrm{bim})_{2}\right] \cdot 0.16 \mathrm{H}_{2} \mathrm{O} \cdot 0.16 \mathrm{C}_{2} \mathrm{H}_{5} \mathrm{OH}(\mathbf{5 3})$, containing 2-chloroimidzaole (2-cim) and 2-bromoimidazole (2-bim) as the ligands, respectively, were prepared using methanol as solvent [72]. The synthetic reaction for 52 was conducted in a glass vial containing a methanol $(4 \mathrm{~mL})$ solution of $\mathrm{Zn}\left(\mathrm{NO}_{3}\right)_{2}(0.4 \mathrm{mmol})$ and 2-cim $(1 \mathrm{mmol})$. The solution was first homogenized by sonication, then covered and heated at $100{ }^{\circ} \mathrm{C}$ in an oven for $2 \mathrm{~d}$, to give colorless polyhedral crystals of 52. Similar to 52, single crystals of $\mathbf{5 3}$ were obtained by reacting $\mathrm{Zn}\left(\mathrm{NO}_{3}\right)_{2}(0.4 \mathrm{mmol})$ and 2-bim $(0.8 \mathrm{mmol})$ in ethanol $(4 \mathrm{~mL})$ for $2 \mathrm{~d}$. Single-crystal X-ray diffraction has revealed that compounds $\mathbf{5 2}$ and $\mathbf{5 3}$ are isostructural to the recently reported ZIF-8 structure (with 2-methylimidazole as ligand) [70] (Fig. 27). In both structures, all $\mathrm{Zn}$ atoms are tetrahedrally coordinated by four $\mathrm{N}$ atoms from the imidazole (IM) ligands. 


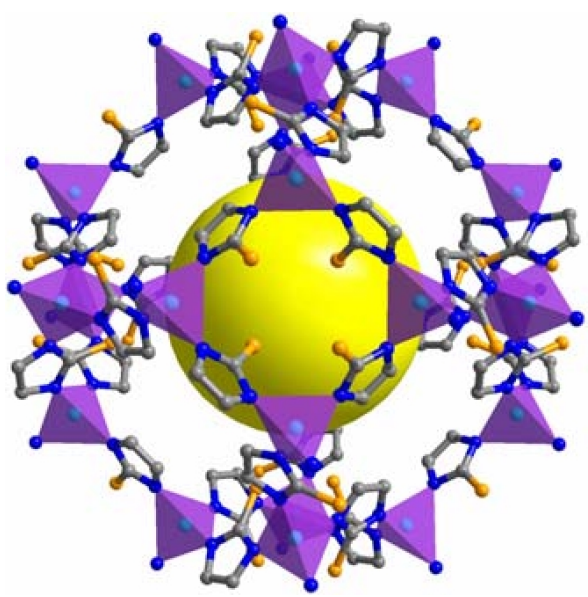

Fig. 27 (color online). View of the pore opening in compound 52. Zn (turquoise), $\mathrm{Cl}$ (orange), $\mathrm{N}$ (blue) and $\mathrm{C}$ (gray).

Each IM ring bridges two $\mathrm{Zn}$ centers through its two N atoms at 1,3-positions to give $\mathrm{Zn}$-IM-Zn angles close to $145^{\circ}$, which is coincident with the $\mathrm{Si}-\mathrm{O}-\mathrm{Si}$ angles of many zeolites. Both, $\mathbf{5 2}$ and $\mathbf{5 3}$ adopt the same expanded sodalite ( $s o d)$ framework structure. The aperture sizes of the square windows in the truncated octahedral cages are almost negligible due to the blockage by the chlorine/bromine atoms. The cages are interconnected through the small openings delimited by $\mathrm{H}$ atoms on imidazolate ligands along the body-diagonal axes of the cubic crystal.

\section{Solvothermal reactions in RTILs}

Besides conventional organic solvents, room temperature ionic liquids (RTILs) can also be chosen as solvothermal reaction media. Due to their unique advantageous properties such as high thermal stability, air and moisture non-sensitivity, non-volatility, low reactivity, and templating and charge balancing ability, solvothermal synthesis in ionic liquids is specifically referred to as ionothermal synthesis [73]. The coordination polymer $\left[\mathrm{Cu}(\mathrm{I})(\mathrm{bpp}) \mathrm{BF}_{4}[\mathrm{bpp}=1,3\right.$-bis $(4-$ pyridyl)propane] (54) was prepared by solvothermal reaction using the ionic liquid $\left[\mathrm{bmim}^{\mathrm{B}}\right]\left[\mathrm{BF}_{4}\right]$ (bmim = 1-butyl-3-methylimidazolium). $\mathrm{Cu}\left(\mathrm{NO}_{3}\right)_{2}$. $3 \mathrm{H}_{2} \mathrm{O}(0.05 \mathrm{mmol})$, bpp $(0.05 \mathrm{mmol})$ and $0.1 \mathrm{~mL}$ of [bmim $]\left[\mathrm{BF}_{4}\right]$ were sealed in a glass tube and heated at $140{ }^{\circ} \mathrm{C}$ for $3 \mathrm{~d}$ to give compound $\mathbf{5 4}$ as columnlike orange crystals [74]. Unlike those compounds obtained by other synthetic approaches, compound $\mathbf{5 4}$ shows a different structure: each $\mathrm{Cu}(\mathrm{I})$ ion is coordinated to two nitrogen atoms from two bpp ligands to (a)

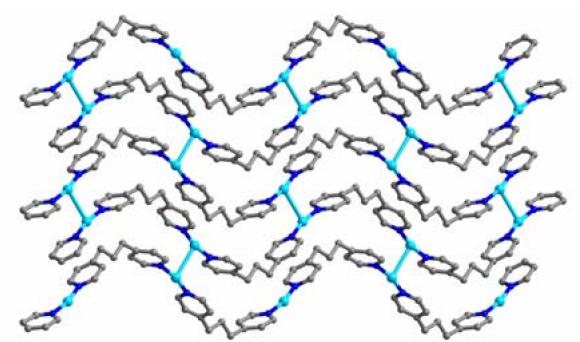

(b)

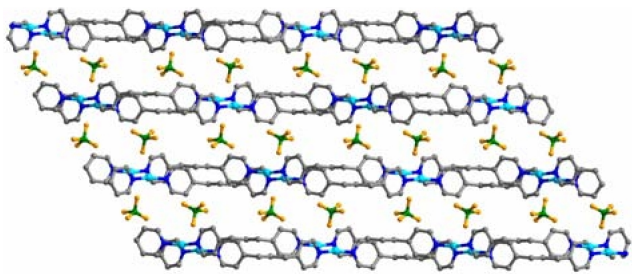

Fig. 28 (color online). View of $\mathbf{5 4}$ along the $c$ axis showing a single layer of $[\mathrm{Cu}(\mathrm{bpp})]^{+}$(a) and along the $b$ axis showing the parallel stacking of the $[\mathrm{Cu}(\mathrm{bpp})]^{+}$layers with $\mathrm{BF}_{4}{ }^{-}$ anions located in between the layers (b). $\mathrm{Cu}$ (turquoise), $\mathrm{N}$ (blue), C (gray), F (orange) and B (green).

form a wave-like $\mathrm{Cu}$-bpp chain. Weak $\mathrm{Cu}-\mathrm{Cu}$ interactions are found between adjacent chains, extending the structure to two-dimensional (Fig. 28). The $\mathrm{BF}_{4}^{-}$anions are found occupying the space between layers as charge-compensating species.

\section{Properties and Multifunctionality}

During the past decade, the chemistry of the infinite one-, two- and three-dimensional (1D, 2D, 3D) coordination frameworks has been an area of rapid growth. Tremendous interests, from physicists, chemists, and materials scientists, have been paid to the diversity and tunability of their structures and properties, as well as to their great potential in traditional and emerging new applications. Our on-going studies described herein exemplify the multifunctionality of such materials in hydrogen storage, hydrocarbon and other small gas sorption and separation, as well as sensing.

\section{Hydrogen adsorption}

Porous materials, particularly porous threedimensional frameworks that we discuss here, have attracted increasing attention due to their ability for gas storage, especially for hydrogen storage. Hydrogen has been considered as a carbon-free clean energy carrier, which can be readily generated from water and hydrocarbons. Among the numerous viable 


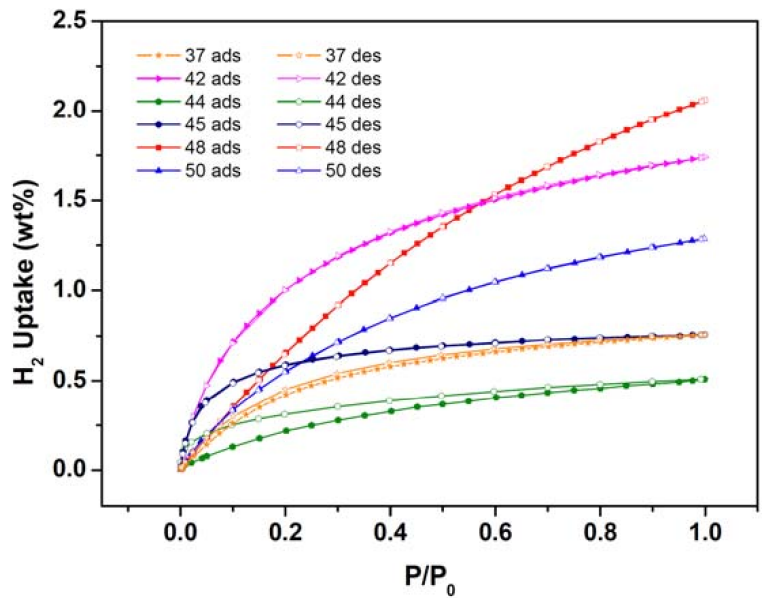

Fig. 29 (color online). $\mathrm{H}_{2}$ adsorption-desorption isotherms of compounds, 37, 42, 44, 45, 48 and 50.

hydrogen storage systems, porous metal coordination frameworks provide some unique advantages [75-78].

Thermal-gravimetric analysis of $\left[M(\mathrm{bdc})(\mathrm{ted})_{0.5}\right]$ ( $M=\mathrm{Zn} \mathrm{48,} \mathrm{Cu} 49$ ) shows the high thermal stability of these two compounds even after removal of all guest solvent molecules. Physical adsorption of argon at low temperature $(87 \mathrm{~K})$ was used to further characterize the porosity of the frameworks. The pore size distributions of 48 and 49 were calculated from $\mathrm{Ar}$ adsorption isotherms at $87 \mathrm{~K}$ using the Horvath-Kawazoe (HK) method, showing that both materials have a very similar pore size distribution of around $7.8 \AA$, consistent with the values determined by the structure analysis. Brunauer-Emmett-Teller (BET) specific surface areas of 1794 and $1461 \mathrm{~m}^{2} \mathrm{~g}^{-1}$, and total pore volumes of 0.65 and $0.52 \mathrm{~cm}^{3} \mathrm{~g}^{-1}$ for $\mathbf{4 8}$ and $\mathbf{4 9}$, respectively, were also obtained from the argon adsorption results.

The hydrogen sorption properties of $\mathbf{4 8}$ and 49 were investigated at 77 and $87 \mathrm{~K}$ (Fig. 29). Their hydrogen adsorption-desorption isotherms were recorded as a function of relative pressure $\left(P / P_{0}\right)$ in the range of $10^{-4}$ to $1 \mathrm{~atm}$. There is no hysteresis observed in the isotherms. The $\mathrm{Zn}$ structure (48) shows a higher $\mathrm{H}_{2}$ uptake ability than the $\mathrm{Cu}$ structure (49) over the whole region. The adsorbed amount of hydrogen corresponds to 2.1 and 1.8 wt.- $\%$ at $77 \mathrm{~K}$ and 1 atm, 1.2 and 1.1 wt. $\%$ at $87 \mathrm{~K}$ and 1 atm for 48 and 49 , respectively. An analysis of the isosteric heats of adsorption $\left(Q_{\mathrm{st}}\right)$ shows the extent of sorbent-sorbate interactions between hydrogen and the frameworks. The $Q_{\text {st }}$ values range roughly from 4.9 to $5.4 \mathrm{~kJ} \mathrm{~mol}^{-1}$ for $\mathbf{4 8}$ for the

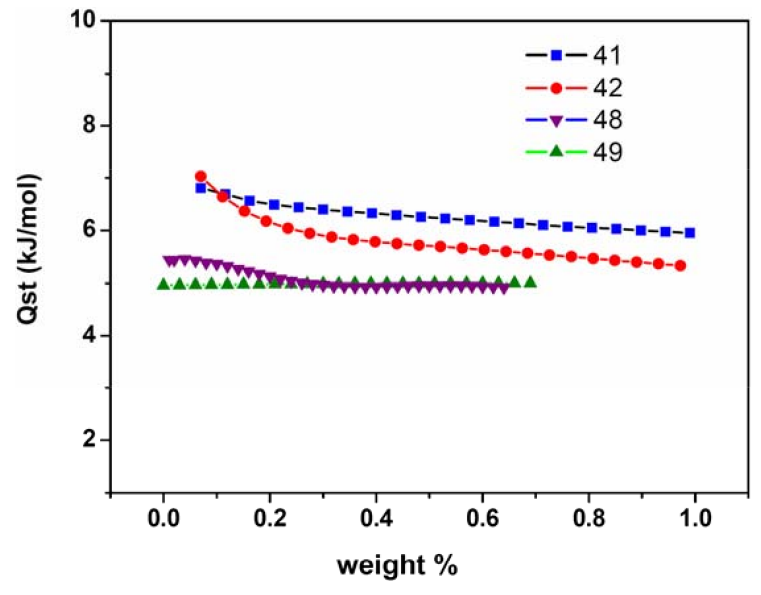

Fig. 30 (color online). Isosteric heats of $\mathrm{H}_{2}$ adsorption for 41, 42, 48 and 49 as a function of the amount of hydrogen adsorbed.

$\mathrm{H}_{2}$ coverage of 0.01 to $0.6 \mathrm{wt} .-\%$, and are around $5.0 \mathrm{~kJ}$ $\mathrm{mol}^{-1}$ for 49 for the $\mathrm{H}_{2}$ coverage of 0.02 to $0.7 \mathrm{wt} .-\%$.

The structures of $\left[\mathrm{Co}_{3}(\mathrm{bpdc})_{3}(\mathrm{bpy})\right]$ (41) and $\left[\mathrm{Zn}_{3}(\mathrm{bpdc})_{3}(\mathrm{bpy})\right](\mathbf{4 2})$ were also chosen for a study of their hydrogen adsorption properties $[60,61]$. Based on the argon adsorption isotherms on compounds $\mathbf{4 1}$ and 42, the Horvath-Kawazoe $(\mathrm{H}-\mathrm{K})$ pore size analysis showed that two types of pores, including ultramicropores (with diameters of $\sim 7 \AA$ ) and supermicropores (with diameters of $\sim 15 \AA$ for $\mathbf{4 1}$ and $10 \AA$ for $\mathbf{4 2}$ ) exist in both compounds, in excellent agreement with the crystallographic data. Analysis of the argon adsorption isotherms gave BET surface areas of 922 and $792 \mathrm{~m}^{2}$ $\mathrm{g}^{-1}$ for $\mathbf{4 1}$ and $\mathbf{4 2}$, respectively. The total pore volumes were estimated to be $0.38 \mathrm{~cm}^{3} \mathrm{~g}^{-1}$ for 41 and $0.33 \mathrm{~cm}^{3}$ $\mathrm{g}^{-1}$ for 42 . The capacities of hydrogen uptake at $77 \mathrm{~K}$ and 1 atm are 1.98 and 1.74 wt.-\% (1.48 and 1.32 wt.$\%$ at $87 \mathrm{~K}$ ) for $\mathbf{4 1}$ and $\mathbf{4 2}$, respectively. Compound 41 shows a higher hydrogen uptake capacity than 42 at all pressure levels, and the calculated isosteric heats of adsorption $\left(Q_{\mathrm{st}}\right)$ at 77 and $78 \mathrm{~K}$ are also higher for $\mathbf{4 1}$ than for 42, suggesting a stronger adsorbent-adsorbate interaction in 41 (Fig. 30). It is worth noting that the very high densities of the adsorbed $\mathrm{H}_{2}\left(0.053 \mathrm{~cm}^{3} \mathrm{~g}^{-1}\right.$ and $0.052 \mathrm{~cm}^{3} \mathrm{~g}^{-1}$ at $77 \mathrm{~K}$ and $1 \mathrm{~atm}$ for 41 and $\mathbf{4 2}$, respectively) at the experimental conditions are nearly comparable to those of liquid $\mathrm{H}_{2}\left(e . g .0 .053 \mathrm{~cm}^{3} \mathrm{~g}^{-1}\right.$ at $30 \mathrm{~K}$ and $8.1 \mathrm{~atm}$ ).

The $\mathrm{H}_{2}$ adsorption at $25^{\circ} \mathrm{C}$ on the guest-free framework compound 36 was performed by charging with hydrogen at increasing pressures up to 48 atm with monitoring the weight change by a pulse mass analyzer 
[55]. Compound 36 shows an almost linearly increasing hydrogen uptake up to $1.0 \mathrm{wt} .-\%$ at $48 \mathrm{~atm}$. This value is comparable with the best performing singlewalled carbon nanotubes (SWNTs). As a further comparison, MOF-5, which has larger pore dimensions of $\sim 7.7 \times 7.7 \AA^{2}$, was also studied [79]. Despite that the accessible pore volumes of MOF-5 are 6.6 times higher than those of $36(76.8 \%$ to $11.6 \%)$, the hydrogen uptake capacity $(1.65 \%$ at $48 \mathrm{~atm})$ of MOF-5 is only 1.8 times that of compound 36. This suggests that the pore volume is not the sole factor that determines the $\mathrm{H}_{2}$ uptake capacity. Other factors, including the pore size and the specific surface area, should be considered as well. Thus tailoring the pore size to fit the molecular diameter of $\mathrm{H}_{2}$ may serve as a working strategy to enhance the $\mathrm{H}_{2}$ storage capacity, in addition to other strategies, such as impregnation, catenation, using lighter metals, and inclusion of unsaturated metal sites, that are all also under active investigation [80].

\section{Small gas separation}

Guest-free metal organic frameworks generally possess ultramicropores $(<7 \AA)$ and exhibit high adsorption selectivity to small gas molecules, which can be used for their separation from other gases [81]. For example, a study of compound $\mathbf{3 7}$ ( $\mathrm{Zn}$ (tbip)) has shown the potential for separation of $\mathrm{MeOH}$ from water and dimethyl ether (DME) [56]. Due to the very hydrophobic nature, compound 37 exhibits essentially zero adsorption ability for water $\left(<\sim 1 \mathrm{mg} \mathrm{g}^{-1}\right.$ at $\left.P / P^{0}=0.65\right)$ but high adsorption ability for methanol, $110 \mathrm{mg} \mathrm{g}^{-1}$ at $24.5^{\circ} \mathrm{C}$ and 90 Torr $\mathrm{MeOH}\left(P / P^{0}=\right.$ 0.73). The $\mathrm{MeOH}$ adsorption isotherms exhibit the typical capillary condensation adsorption behavior with very little of $\mathrm{MeOH}$ adsorbed up to 40 Torr (less than $\sim 3 \mathrm{mg} \mathrm{g}^{-1}$ ) and a very sharp increase in adsorption beyond 40 Torr. Isotherms at various temperatures show that the condensation point of $\mathrm{MeOH}$ shifts to higher $P / P^{0}$ with increasing temperature by around 4.7 Torr ${ }^{\circ} \mathrm{C}^{-1}$ (Fig. 31a). The adsorption isotherms of $\mathrm{DME}$ and $\mathrm{MeOH}$ indicate that compound $\mathbf{3 7}$ has the potential to selectively adsorb DME at conditions of $T$ and $P$ below the capillary condensation point of $\mathrm{MeOH}$ (Fig. 31b). In addition, in the adsorption of the binary gases of DME and $\mathrm{MeOH}$ a temperature increase of a few degrees shifts the capillary condensation point of $\mathrm{MeOH}$ to higher pressure, resulting in desorption of the majority of the $\mathrm{MeOH}$ adsorbed and of a relatively small amount of DME. This suggests that temperature (a)

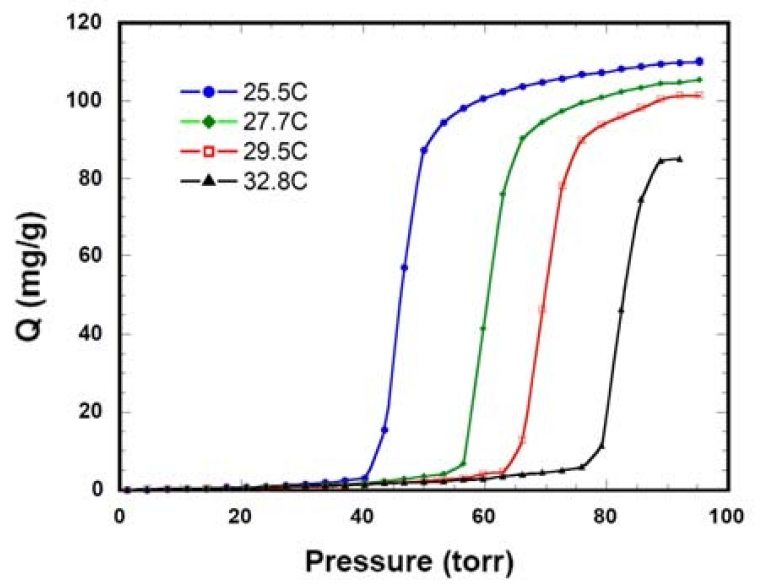

(b)

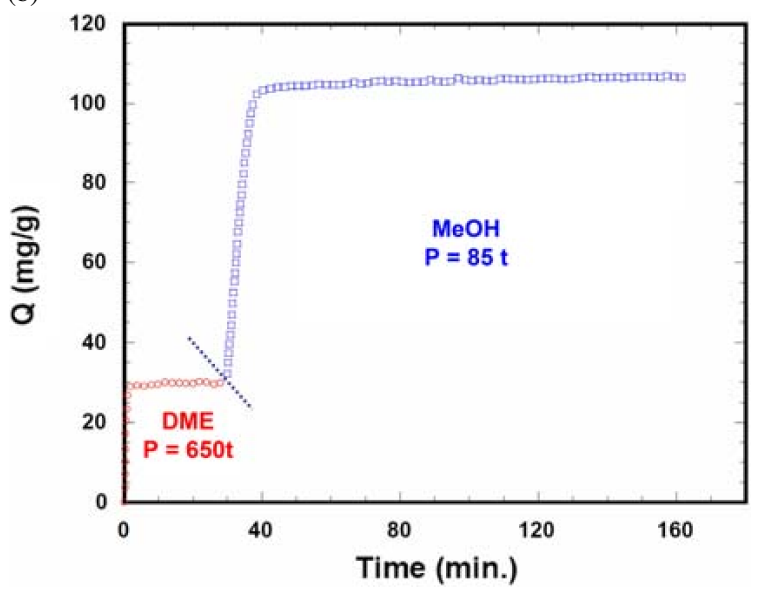

Fig. 31 (color online). $\mathrm{MeOH}$ adsorption isotherms at different temperatures (a) and adsorption of DME at $30{ }^{\circ} \mathrm{C}$ followed by $\mathrm{MeOH}$ adsorption in compound $\mathbf{3 7}$ as a function of time (b).

can play a critical role in the separation of DME and $\mathrm{MeOH}$.

Compounds 48 and 49 exhibit similar, but much more efficient $\mathrm{MeOH}$ adsorption performance, $520 \mathrm{mg}$ $\mathrm{g}^{-1}$ at $25^{\circ} \mathrm{C}$ and 60 Torr. The capillary condensation adsorption behavior could also be observed in both $\mathrm{MeOH}$ and EtOH adsorption studies, but not for DME. This difference can be attributed to the existence of H-bonding between frameworks and the alcohol molecules, which is absent for DME. Because of the high hydrophobic surface of $\mathbf{4 8}$ and $\mathbf{4 9}$, adsorption of only $\sim 6 \mathrm{mg} \mathrm{g}^{-1}$ of water was recorded at $P / P^{0}=0.42$, which is less than the adsorption capacity $(>400 \mathrm{mg}$ $\mathrm{g}^{-1}$ ) for $\mathrm{MeOH}, \mathrm{EtOH}$ and DME. Our study also indicated that the hydrocarbons with hydrophobic methyl 


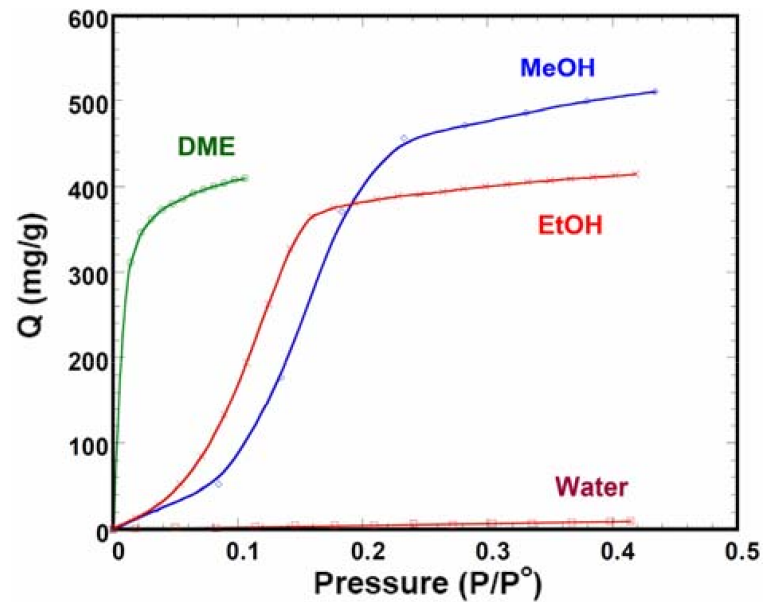

Fig. 32 (color online). Methanol, ethanol, dimethyl ether and water adsorption isotherms for compound 48 at $30{ }^{\circ} \mathrm{C}$.

groups can be easily separated from water in watercontaining gas-phase mixtures (Fig. 32).

\section{Hydrocarbon sorption and separation}

In contrast to the enormous research efforts on small molecule $\left(\mathrm{H}_{2}, \mathrm{~N}_{2}, \mathrm{Ar}, \mathrm{CO}_{2}, \mathrm{CH}_{4}\right.$, etc. $)$ gas adsorption by metal-organic frameworks, the research on hydrocarbon adsorption and separation has been still quite limited [79,82]. Considering the vast diversity and tunability of their frameworks and pore structures, in terms of pore size, shape and surface character-

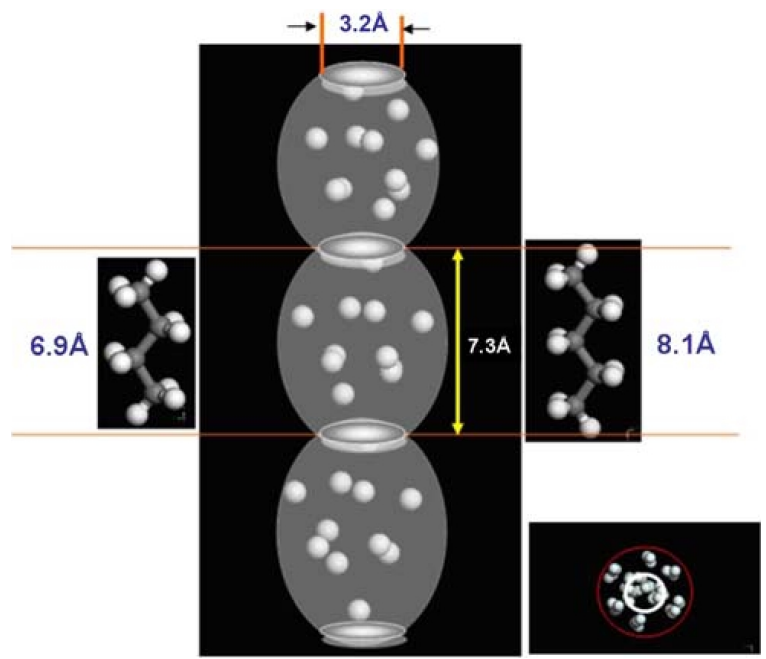

Fig. 33 (color online). A schematic view of the microchannel in compound $\mathbf{3 6}$ to show the sizes of the oval-shaped cages and the opening of the neck regions which are the critical factors for selective hydrocarbon adsorption.
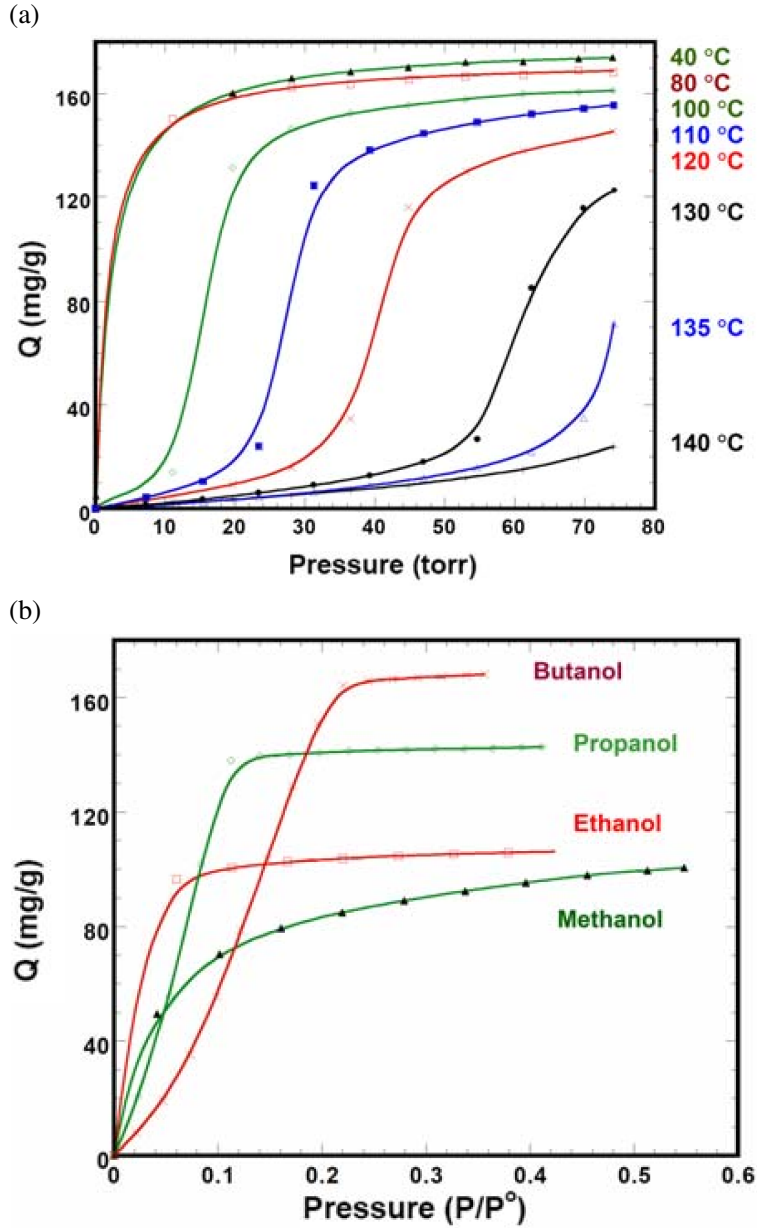

Fig. 34 (color online). Benzene adsorption isotherms at different temperatures (a) and light alcohol adsorption isotherms (b) for compound $\mathbf{4 5}$.

istics, porous metal-organic framework materials are also promising candidates for hydrocarbon adsorption and separation.

Compound 36, to the best of our knowledge, is the first material exhibiting the ability to separate normal C2-C4 olefins and alkanes from all higher branched alkanes and normal hydrocarbons [83]. In spite of its very small pore volume, compound $\mathbf{3 6}$ exhibits unique adsorption capacity for propane and butane over pentane or higher normal or branched hydrocarbons. This unusual property can be attributed to the special pore structure. The narrow channels in $\mathbf{3 6}$ can be viewed as alternating oval-shaped cages connected through narrow "neck" regions. This structural feature is better manifested by helium adsorption simulation (Fig. 33). The length of the large chamber $(\sim 7.3 \AA)$ is just 
longer than the length of $n$-C4 $(\sim 6.9 \AA)$ molecules and shorter than $n$-C5 molecules ( $8.1 \AA$ ). The diameter of the "neck" regions is calculated as $3.2 \AA$ (excluding the van der Waals radius of carbon), which rules out equilibrium positions for a normal alkane $(>n-\mathrm{C} 5)$ at the neck regions. However, the size of the neck is just large enough to allow the passage of normal alkanes, but not branched alkanes.

Compound $\left[\mathrm{Co}_{3}(\mathrm{HCOO})_{6}\right] \mathbf{4 5}$ and its hydrocarbon adsorption capacity and selectivity were systematically studied (Fig. 34) [64]. Benzene adsorption isotherms have shown that $\mathbf{4 5}$ can adsorb 3.94 molecules of benzene per unit cell, in agreement with the simulated result of 3.73 molecules per unit cell in the same temperature and pressure region. Both experimental data and simulations suggest a commensurate accommodation of benzene in the channels of $\mathbf{4 5}$. Compared with benzene, the adsorption isotherms for toluene, ethylbenzene and $p$-xylene of $\mathbf{4 5}$ reveal that the number of molecules adsorbed per unit cell decreases monotonically for this series, which can be attributed to the increasing steric constraint and rigidity from toluene to ethylbenzene to $p$-xylene.

A study of the adsorption of light alcohols, from methanol to pentanol, has also demonstrated the controlling role of the channel structure of compound $\mathbf{4 5}$. When the EtOH isotherm is already flat at $30{ }^{\circ} \mathrm{C}$ and high pressure, the isotherm for $\mathrm{MeOH}$ still has a significant positive slope in the same region, indicating the arrival of the adsorption limit for $\mathrm{EtOH}$ but not for $\mathrm{MeOH}$. From the isotherms, EtOH as well as $\mathrm{C} 3$ and $\mathrm{C} 4$ alcohols, all have an adsorption maximum of 4 molecules per unit cell, suggesting the commensurate accommodation of these molecules in the channel of compound 45. $\mathrm{MeOH}$ does not have this loading limit due to its smaller size. Adsorption isotherms also suggest that compound $\mathbf{4 5}$ has a higher affinity to $\mathrm{EtOH}$ over $\mathrm{MeOH}$ due to the $\mathrm{CH}_{2}$ group interacting with the framework, which is consistent with the expected increase in the isosteric heats of adsorption.

A similar effect of commensurate pore shape-guest molecule accommodation is found in the propane adsorption by $\mathbf{4 5}$. As a molecule of a length comparable to that of EtOH (5.84 $\AA$ vs. $5.64 \AA$ ), propane also has an adsorption limit of 4 molecules per unit cell, but for hexane with a size $(10.20 \AA)$ twice that of propane, the loading limit decreases to 2.1 molecules per unit cell, roughly $1 / 2$ that of propane. For most adsorbents studied, the isosteric heats of adsorption were essentially constant for the loading level, indicating that

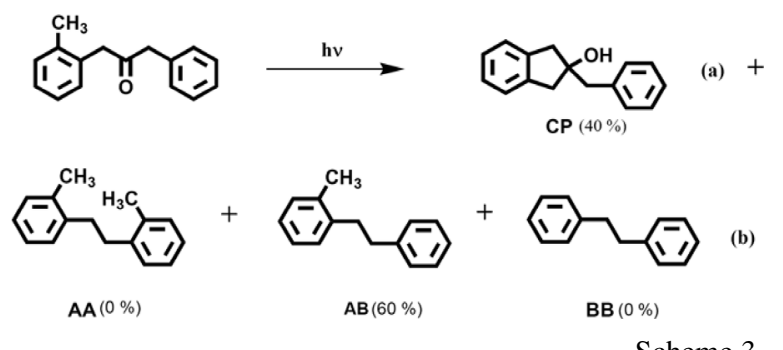

Scheme 3.

the adsorption is mainly controlled by the adsorbateadsorbent interactions rather than adsorbate-adsorbate interactions.

\section{Ship-in-bottle synthesis}

The well-defined pores in MOFs offer them great potential as hosts for size- and shape-selective reactions, such as "ship-in-bottle" synthesis [84]. In a "ship-in-bottle" reaction, synthesis is conducted within a framework containing an internal cavity (bottle) to give the product (ship) generally with high selectivity. The porosity and the unique $3 \mathrm{D} \leftrightarrow 1 \mathrm{D}$ recyclable interconversion found in compound $\mathbf{4 1}$ make it an interesting "bottle" for special synthesis reactions [61]. Based on earlier work on the photochemistry of dibenzylketon $(\mathrm{DBK})$ and derivatives inside a zeolite, $o$-MeDBK will undergo two photoreactions: (a) an intramolecular hydrogen abstraction followed by cyclization with formation of a cyclopentanol, $\mathbf{C P}$, and (b) an $\alpha$-cleavage followed by removal of carbon monoxide with the formation of a pair of hydrocarbon radicals, which further undergo geminate (product $\mathbf{A B}$ ) or random combination (products $\mathbf{A A}, \mathbf{A B}$, and $\mathbf{B B}$ ) (Scheme 3) [85]. When $o$-MeDBK is adsorbed by compound 41, analysis has revealed that photolysis produces CP with $40 \%$ yield in reaction (a) and $\mathbf{A B}$ with $60 \%$ yield in reaction (b), and that both yields are much higher than those values found in a zeolites "ship". More importantly, direct extraction from the "broken bottle" with the structure conversion from $3 \mathrm{D}$ to $1 \mathrm{D}$ non-porous precursor releases the products to reach a $100 \%$ mass balance. This study suggests the unique potential of the frameworks with certain pores or channels to serve as "smart" porous host for "ship-in-bottle" reactions or other syntheses.

\section{Luminescence, sensing and detection}

MOFs also offer a unique platform for the development of solid-state luminescent materials, and there 


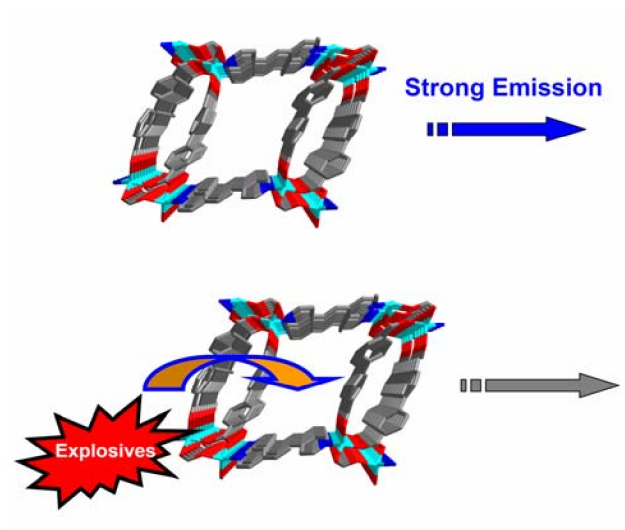

Fig. 35 (color online). A schematic illustration of the luminescence quenching of compound $\mathbf{4 4}$ induced by explosives. have been reported numerous MOFs with interesting light emitting properties [86,87]. The combination of the porous and luminescent nature of such materials endows them with the capability of transducing the host-guest chemistry to detectable signals, e.g. to changes of luminescence, making them promising candidates for sensing applications. The highly luminescent microporous metal-organic framework $\left[\mathrm{Zn}_{2}(\text { bpdc })_{2}\right.$ (bpee) $]$ (44) exhibits very fast and reversible quenching of its luminescence upon exposure to the vapors of electron-deficient compounds, e.g. DNT (2,4-dinitrotoluene) and DMNB (2,3-dimethyl2,3-dinitrobutane) [63]. (Fig. 35). When a guest-free sample of $\mathbf{4 4}$ is exposed to equilibrated vapors of DNT or DMNB, very rapid (within 10 seconds) and close to complete fluorescence quench for both DNT $(\sim 85 \%)$ and DMNB $(\sim 84 \%)$ are recorded. There are also guest-dependent red-shifts of the fluorescence peaks accompanying the quenching process, indicative of guest-dependent interactions between the host framework and the analytes. More significantly, the photoluminescence of $\mathbf{4 4}$ can be fully recovered by simply heating the material at $150{ }^{\circ} \mathrm{C}$ for about one minute. Since DNT and DMNB are closely associated with high explosives, 44 might be used for fast and reversible detection of explosives. Previous studies on conjugated polymer thin films and other sensing materials have demonstrated that higher dimensionality may enhance sensitivity, because the excitons can be effectively quenched by increasing analyte binding sites through delocalization over the conjugated backbone ("molecular wire" effect), through interchain en- ergy migration in the solid state, or through a highly organized molecular stacking structure [88]. Accordingly, the infinite three-dimensional framework structure of compound $\mathbf{4 4}$ with well-ordered $\pi$ systems will facilitate quenching of the excitons through similar mechanisms.

\section{Summary}

In this review, we have presented the result of our work on the construction of coordination polymers carried out in the last decade. It has been shown how 1D, 2D and 3D networks are formed via hydrothermal and solvothermal synthesis methods, and the influences by numerous experiment parameters, such as solvent, $\mathrm{pH}$, composition, temperature and pressure have been demonstrated. Our study has shown that the diversity of the networks is directly related to the choice of the vertex geometry and the organic linkers. Thus by choosing elaborately designed building blocks and organic ligands, the formation of coordination polymers with different topology and dimensionality can be controlled, and striking properties and multifunctionality, including those relevant to gas storage and separation, hydrocarbon adsorption and separation, catalysis and optical sensing, could be achieved.

\section{Acknowledgements}

The authors would like to thank the Department of Energy (DOE) for the financial support through Grant No. DEFG36-08GO18139. We would also like to thank Dr. L. Pan, Dr. X. Y. Huang, Dr. D. H. Olson, Dr. J. Y. Lee, Dr. T. J. Emge, and A. J. Lan for their contributions. 
[1] O. M. Yaghi, H. L. Li, C. Davis, D. Richardson, T. L. Groy, Acc. Chem. Res. 1998, 31, 474.

[2] G. Férey, Chem. Soc. Rev. 2008, 37, 191.

[3] S. Kitagawa, S. Kawata, Coord. Chem. Rev. 2002, 224, 11.

[4] B. F. Hoskins, R. Robson, J. Am. Chem. Soc. 1989, 111, 5962.

[5] C. Janiak, Angew. Chem. 1997, 109, 1499; Angew. Chem., Int. Ed. Engl. 1997, 36, 1431.

[6] A. J. Blake, N. R. Champness, P. Hubberstey, W. S. Li, M. A. Withersby, M. Schroder, Coord. Chem. Rev. 1999, $183,117$.

[7] A. Y. Robin, K. M. Fromm, Coord. Chem. Rev. 2006, $250,2127$.

[8] B. Moulton, M. J. Zaworotko, Chem. Rev. 2001, 101, 1629.

[9] S. R. Batten, R. Robson, Angew. Chem. 1998, 110, 1558; Angew. Chem. Int. Ed. 1998, 37, 1460.

[10] M. Eddaoudi, D. B. Moler, H. L. Li, B. L. Chen, T. M. Reineke, M. O'Keeffe, O. M. Yaghi, Acc. Chem. Res. 2001, 34, 319.

[11] S. Kitagawa, R. Kitaura, S. Noro, Angew. Chem. 2004, 116, 2388; Angew. Chem. Int. Ed. 2004, 43, 2334.

[12] C. Janiak, Dalton Trans. 2003, 2781.

[13] D. Maspoch, D. Ruiz-Molina, J. Veciana, Chem. Soc. Rev. 2007, 36, 770.

[14] A. U. Czaja, N. Trukhan, U. Muller, Chem. Soc. Rev. 2009, 38, 1284.

[15] A. Y. Robin, K. M. Fromm, H. Goesmann, G. Bernardinelli, Cryst. Eng. Comm. 2003, 5, 405.

[16] B. F. Hoskins, R. Robson, J. Am. Chem. Soc. 1990, 112, 1546.

[17] R. Robson, J. Chem. Soc., Dalton Trans. 2000, 3735.

[18] A.F. Wells, Three-Dimensional Nets and Polyhedra, Wiley, New York, 1977.

[19] M. J. Zaworotko, Chem. Soc. Rev. 1994, 23, 283.

[20] M. J. Zaworotko, Chem. Commun. 2001, 1.

[21] M. Fujita, Y. J. Kwon, S. Washizu, K. Ogura, J. Am. Chem. Soc. 1994, 116, 1151.

[22] M. C. Hong, Y. J. Zhao, W. P. Su, R. Cao, M. Fujita, Z. Y. Zhou, A. S. C. Chan, Angew. Chem. 2000, 112, 2586; Angew. Chem. Int. Ed. 2000, 39, 2468.

[23] S. Noro, S. Kitagawa, M. Kondo, K. Seki, Angew. Chem. 2000, 112, 2161; Angew. Chem. Int. Ed. 2000, 39, 2082.

[24] R. Kitaura, S. Kitagawa, Y. Kubota, T. C. Kobayashi, K. Kindo, Y. Mita, A. Matsuo, M. Kobayashi, H. C. Chang, T. C. Ozawa, M. Suzuki, M. Sakata, M. Takata, Science 2002, 298, 2358.

[25] R. Kitaura, K. Fujimoto, S. Noro, M. Kondo, S. Kitagawa, Angew. Chem. 2002, 114, 141; Angew. Chem. Int. Ed. 2002, 41, 133.

[26] C. Livage, N. Guillou, J. Marrot, G. Férey, Chem. Mater. 2001, 13, 4387.
[27] C. Serre, C. Férey, J. Mater. Chem. 2002, 12, 3053.

[28] H. Li, M. Eddaoudi, T. L. Groy, O. M. Yaghi, J. Am. Chem. Soc. 1998, 120, 8571.

[29] O. M. Yaghi, C.E. Davis, G. M. Li, H.L. Li, J. Am. Chem. Soc. 1997, 119, 2861.

[30] H. L. Li, C.E. Davis, T. L. Groy, D. G. Kelley, O. M. Yaghi, J. Am. Chem. Soc. 1998, 120, 2186.

[31] H. Li, M. Eddaoudi, M. O'Keeffe, O. M. Yaghi, Nature 1999, 402, 276.

[32] O. M. Yaghi, H. L. Li, J. Am. Chem. Soc. 1995, 117, 10401.

[33] J. Li, Z. Chen, R. J. Wang, D. M. Proserpio, Coord. Chem. Rev. 1999, 192, 707.

[34] X. M. Chen, M.L. Tong, Acc. Chem. Res. 2007, 40, 162.

[35] S. M. F. Lo, S. S. Y. Chui, L. Y. Shek, Z. Y. Lin, X. X. Zhang, G. H. Wen, I. D. Williams, J. Am. Chem. Soc. 2000, 122, 6293.

[36] J. L. C. Rowsell, O.M. Yaghi, Microporous Mesoporous Mater. 2004, 73, 3.

[37] G. Demazeau, J. Mater. Sci. 2008, 43, 2104.

[38] J. Y. Lu, B. R. Cabrera, R. J. Wang, J. Li, Inorg. Chem. 1998, 37, 4480.

[39] J. Y. Lu, B. R. Cabrera, R. J. Wang, J. Li, Inorg. Chem. 1999, 38, 4608.

[40] J. Y. Lu, M. A. Lawandy, J. Li, T. Yuen, C. L. Lin, Inorg. Chem. 1999, 38, 2695.

[41] M. A. Lawandy, X. Y. Huang, R. J. Wang, J. Li, J. Y. Lu, T. Yuen, C. L. Lin, Inorg. Chem. 1999, 38, 5410.

[42] T. M. Reineke, M. Eddaoudi, M. Fehr, D. Kelley, O. M. Yaghi, J. Am. Chem. Soc. 1999, 121, 1651.

[43] D. L. Long, A. J. Blake, N. R. Champness, C. Wilson, M. Schroder, Angew. Chem. 2001, 113, 2509; Angew. Chem. Int. Ed. 2001, 40, 2444.

[44] L. Pan, X. Y. Huang, J. Li, Y. G. Wu, N. W. Zheng, Angew. Chem. 2000, 112, 537; Angew. Chem. Int. Ed. 2000, 39, 527.

[45] L. Pan, X. Y. Huang, J. Li, J. Solid State Chem. 2000, 152, 236.

[46] L.F. Ma, L. Y. Wang, X. K. Huo, Y. Y. Wang, Y. T. Fan, J. G. Wang, S. H. Chen, Cryst. Growth Des. 2008, 8, 620.

[47] R. G. Harrison, O. D. Fox, M. O. Meng, N. K. Dalley, L. J. Barbour, Inorg. Chem. 2002, 41, 838.

[48] L. Pan, T. Frydel, M. B. Sander, X. Y. Huang, J. Li, Inorg. Chem. 2001, 40, 1271.

[49] O. M. Yaghi, G. M. Li, H. L. Li, Nature 1995, 378, 703.

[50] L. Pan, N. Ching, X. Y. Huang, J. Li, Inorg. Chem. 2000, 39, 5333.

[51] L. Pan, N. W. Zheng, Y. G. Wu, S. Nan, R. Y. Yang, X. Y. Huang, J. Li, Inorg. Chem. 2001, 40, 828.

[52] A. H. Fu, J. Y. Lu, X. Y. Huang, J. Li, J. Alloys Compd. 2001, 319, 89. 
[53] L. Pan, N. Ching, X. Y. Huang, J. Li, Chem. Commun. 2001, 1064.

[54] L. Pan, N. Ching, X. Y. Huang, J. Li, Chem. Eur. J. 2001, 7, 4431.

[55] L. Pan, M. B. Sander, X. Y. Huang, J. Li, M. Smith, E. Bittner, B. Bockrath, J. K. Johnson, J. Am. Chem. Soc. 2004, 126, 1308.

[56] L. Pan, B. Parker, X. Y. Huang, D. H. Olson, J. Lee, J. Li, J. Am. Chem. Soc. 2006, 128, 4180.

[57] R. K. Kumar, I. Goldberg, Angew. Chem. 1998, 110, 3176; Angew. Chem. Int. Ed. 1998, 37, 3027.

[58] L. Pan, S. Kelly, X. Y. Huang, J. Li, Chem. Commun. 2002, 2334.

[59] L. Pan, X. Y. Huang, H. L. N. Phan, T. J. Emge, J. Li, X. T. Wang, Inorg. Chem. 2004, 43, 6878.

[60] J. Y. Lee, L. Pan, S. R. Kelly, J. Jagiello, T. J. Emge, J. Li, Adv. Mater. 2005, 17, 2703.

[61] L. Pan, H. M. Liu, X. G. Lei, X. Y. Huang, D. H. Olson, N. J. Turro, J. Li, Angew. Chem. 2003, 115, 560; Angew. Chem. Int. Ed. 2003, 42, 542.

[62] L. Pan, H. M. Liu, S. P. Kelly, X. Y. Huang, D. H. Olson, J. Li, Chem. Commun. 2003, 854.

[63] A. J. Lan, K. H. Li, H. H. Wu, D. H. Olson, T. J. Emge, W. Ki, M. C. Hong, J. Li, Angew. Chem. 2009, 121, 2370; Angew. Chem. Int. Ed. 2009, 48, 2334.

[64] K.H. Li, D. H. Olsan, J. Y. Lee, W.H. Bi, K. Wu, T. Yuen, Q. Xu, J. Li, Adv. Funct. Mater. 2008, 18, 2205.

[65] D. N. Dybtsev, H. Chun, K. Kim, Angew. Chem. 2004, 116, 5143; Angew. Chem. Int. Ed. 2004, 43, 5033.

[66] J. Y. Lee, D. H. Olson, L. Pan, T. J. Emge, J. Li, $A d v$. Funct. Mater. 2007, 17, 1255.

[67] B. L. Chen, M. Eddaoudi, T. M. Reineke, J. W. Kampf, M. O’Keeffe, O. M. Yaghi, J. Am. Chem. Soc. 2000, 122, 11559.

[68] J. Kim, B. L. Chen, T. M. Reineke, H. L. Li, M. Eddaoudi, D. B. Moler, M. O'Keeffe, O. M. Yaghi, J. Am. Chem. Soc. 2001, 123, 8239.

[69] K. H. Li, J. Lee, D. H. Olson, T. J. Emge, W. H. Bi, M. J. Eibling, J. Li, Chem. Commun. 2008, 6123.

[70] K.S. Park, Z. Ni, A.P. Cote, J. Y. Choi, R. D. Huang, F. J. Uribe-Romo, H. K. Chae, M. O'Keeffe, O. M. Yaghi, Proc. Natl. Acad. Sci. 2006, 103, 10186.

[71] R. Banerjee, A. Phan, B. Wang, C. Knobler, H. Fu- rukawa, M. O'Keeffe, O. M. Yaghi, Science 2008, 319, 939.

[72] K.H. Li, D. H. Olson, J. Seidel, T.J. Emge, H. W. Gong, H. P. Zeng, J. Li, J. Am. Chem. Soc. 2009, 131, 10368.

[73] W. M. Reichert, J. D. Holbrey, K. B. Vigour, T. D. Morgan, G. A. Broker, R. D. Rogers, Chem. Commun. 2006, 4767.

[74] K. Jin, X. Y. Huang, L. Pang, J. Li, A. Appel, S. Wherland, Chem. Commun. 2002, 2872.

[75] N.L. Rosi, J. Eckert, M. Eddaoudi, D. T. Vodak, J. Kim, M. O'Keeffe, O. M. Yaghi, Science 2003, 300, 1127.

[76] B. L. Chen, N. W. Ockwig, A. R. Millward, D. S. Contreras, O. M. Yaghi, Angew. Chem. 2005, 117, 4823; Angew. Chem. Int. Ed. 2005, 44, 4745.

[77] J. L. C. Rowsell, E. C. Spencer, J. Eckert, J.A. K. Howard, O. M. Yaghi, Science 2005, 309, 1350.

[78] L. J. Murray, M. Dinca, J. R. Long, Chem. Soc. Rev. 2009, 38, 1294.

[79] M. Eddaoudi, J. Kim, N. Rosi, D. Vodak, J. Wachter, M. O'Keeffe, O. M. Yaghi, Science 2002, 295, 469.

[80] J. L. C. Rowsell, O. M. Yaghi, Angew. Chem. 2005, 117, 4748; Angew. Chem. Int. Ed. 2005, 44, 4670.

[81] R. Matsuda, R. Kitaura, S. Kitagawa, Y. Kubota, R. V. Belosludov, T. C. Kobayashi, H. Sakamoto, T. Chiba, M. Takata, Y. Kawazoe, Y. Mita, Nature 2005, 436, 238.

[82] B. L. Chen, C. D. Liang, J. Yang, D. S. Contreras, Y. L. Clancy, E. B. Lobkovsky, O. M. Yaghi, S. Dai, Angew. Chem. 2006, 118, 1418; Angew. Chem. Int. Ed. 2006, $45,1390$.

[83] L. Pan, D. H. Olson, L. R. Ciemnolonski, R. Heddy, J. Li, Angew. Chem. 2006, 118, 632; Angew. Chem. Int. Ed. 2006, 45, 616.

[84] N. J. Turro, Acc. Chem. Res. 2000, 33, 637.

[85] X. G. Lei, C. E. Doubleday, M. B. Zimmt, N. J. Turro, J. Am. Chem. Soc. 1986, 108, 2444.

[86] C. A. Bauer, T. V. Timofeeva, T. B. Settersten, B. D. Patterson, V. H. Liu, B. A. Simmons, M. D. Allendorf, J. Am. Chem. Soc. 2007, 129, 7136.

[87] M. D. Allendorf, C. A. Bauer, R. K. Bhakta, R. J. T. Houk, Chem. Soc. Rev. 2009, 38, 1330.

[88] S. W. Thomas, G. D. Joly, T. M. Swager, Chem. Rev. 2007, 107, 1339. 